\title{
Cannabidiol and Sports Performance: a Narrative Review of Relevant Evidence and Recommendations for Future Research
}

Danielle McCartney ${ }^{1,2,3^{*}}$ (D) Melissa J. Benson ${ }^{1,2,3}$, Ben Desbrow ${ }^{4}$, Christopher Irwin ${ }^{4,5}$, Anastasia Suraev ${ }^{1,2,3}$ and lain S. McGregor $r^{1,2,3}$

\begin{abstract}
Cannabidiol (CBD) is a non-intoxicating cannabinoid derived from Cannabis sativa. CBD initially drew scientific interest due to its anticonvulsant properties but increasing evidence of other therapeutic effects has attracted the attention of additional clinical and non-clinical populations, including athletes. Unlike the intoxicating cannabinoid, $\Delta^{9}$-tetrahydrocannabinol $\left(\Delta^{9}\right.$-THC), CBD is no longer prohibited by the World Anti-Doping Agency and appears to be safe and well-tolerated in humans. It has also become readily available in many countries with the introduction of over-the-counter "nutraceutical" products. The aim of this narrative review was to explore various physiological and psychological effects of CBD that may be relevant to the sport and/ or exercise context and to identify key areas for future research. As direct studies of CBD and sports performance are is currently lacking, evidence for this narrative review was sourced from preclinical studies and a limited number of clinical trials in non-athlete populations. Preclinical studies have observed robust anti-inflammatory, neuroprotective and analgesic effects of CBD in animal models. Preliminary preclinical evidence also suggests that CBD may protect against gastrointestinal damage associated with inflammation and promote healing of traumatic skeletal injuries. However, further research is required to confirm these observations. Early stage clinical studies suggest that CBD may be anxiolytic in "stress-inducing" situations and in individuals with anxiety disorders. While some case reports indicate that CBD improves sleep, robust evidence is currently lacking. Cognitive function and thermoregulation appear to be unaffected by CBD while effects on food intake, metabolic function, cardiovascular function, and infection require further study. CBD may exert a number of physiological, biochemical, and psychological effects with the potential to benefit athletes. However, well controlled, studies in athlete populations are required before definitive conclusions can be reached regarding the utility of CBD in supporting athletic performance.
\end{abstract}

Keywords: Cannabidiol, CBD, Cannabis, Cannabinoid, Athletic performance, Exercise

\footnotetext{
* Correspondence: danielle.mccartney@sydney.edu.au

'The University of Sydney, Faculty of Science, School of Psychology, Sydney,

New South Wales 2050, Australia

${ }^{2}$ The University of Sydney, Lambert Initiative for Cannabinoid Therapeutics,

Sydney, New South Wales, Australia

Full list of author information is available at the end of the article
}

\section{Springer Open}

(c) The Author(s). 2020 Open Access This article is licensed under a Creative Commons Attribution 4.0 International License, which permits use, sharing, adaptation, distribution and reproduction in any medium or format, as long as you give appropriate credit to the original author(s) and the source, provide a link to the Creative Commons licence, and indicate if changes were made. The images or other third party material in this article are included in the article's Creative Commons licence, unless indicated otherwise in a credit line to the material. If material is not included in the article's Creative Commons licence and your intended use is not permitted by statutory regulation or exceeds the permitted use, you will need to obtain permission directly from the copyright holder. To view a copy of this licence, visit http://creativecommons.org/licenses/by/4.0/. 


\section{Key Points}

- CBD has been reported to exert a number of physiological, biochemical, and psychological effects that have the potential to benefit athletes.

- The available evidence is preliminary, at times inconsistent, and largely based on preclinical studies involving laboratory animals.

- Rigorous, controlled investigations clarifying the utility of CBD in the sporting context are warranted.

\section{Introduction}

Cannabis sativa contains numerous chemical compounds with potential bioactive effects, including at least 144 cannabinoids $[56,76]$. The most studied of the cannabinoids are $\Delta^{9}$-tetrahydrocannabinol $\left(\Delta^{9}-\mathrm{THC}\right)$, renowned for its distinctive intoxicating effects [73, 123], and cannabidiol (CBD) - a non-intoxicating cannabinoid that is particularly enriched in industrial hemp cultivars grown for seed and fibre [61]. CBD was first isolated in 1940 and initially considered to be biologically inactive, with no apparent therapeutic or "subjective" drug effects [1]. However, in 1973, Carlini et al. [27] demonstrated anticonvulsant effects of CBD in a preclinical model, which were later mirrored in humans suffering from intractable epilepsy [46]. A subsequent rise in research into CBD [206] has uncovered interactions with numerous molecular targets [92] and a range of potential therapeutic applications [138]. Following successful phase 3 clinical trials $[53,54,172]$, the oral CBD solution, Epidiolex ${ }^{\circ}$, has also recently gained Food and Drug Administration approval as a regulated prescription medication to treat certain forms of paediatric epilepsy.

Recently, interest in CBD has intensified among the general population as evidenced by an exponential rise in internet searches for 'CBD' in the United States (USA) [108]. Some professional athletes (e.g. golfers, rugby players) also appear to be using CBD (e.g. 'Team cbdMD' https://www.cbdmd.com/), despite there being no published studies demonstrating beneficial effects on sport or exercise performance. In many jurisdictions, including the USA and Europe, access to regulated, prescription CBD (i.e. Epidiolex ${ }^{\circ}$ ) is limited to patients with intractable epilepsy. However, a wide range of low dose (e.g. 5-50 mg. $\mathrm{d}^{-1}$ ) CBD-containing "nutraceuticals" (primarily in oil or capsule form) have become readily available online and over-the-counter (e.g. pharmacies, health food stores) [20, 125]. This includes some varieties that are marketed specifically to recreational and elite athletes (e.g. cbdMD, fourfivecbd). The use of these products is likely to become even more widespread if the World Health Organization's recommendation that CBD no longer be scheduled in the international drug control conventions is adopted by the United Nations member states [201].

Cannabis has been prohibited in all sports during competition since the World Anti-Doping Agency first assumed the responsibility of establishing and maintaining the list of prohibited substances in sport 15 years ago [89]. In 2018, however, CBD was removed from the Prohibited List [199], presumably on the basis of mounting scientific evidence that the cannabinoid is safe and well-tolerated in humans $[16,169]$, even at very high doses (e.g. 1500 $\mathrm{mg}$ day $^{-1}$ or as an acute dose of $6000 \mathrm{mg}$ ) [170]. While several recent reviews have described the impact of cannabis on athlete health and performance [99, 176, 188], the influence of CBD alone has yet to be addressed.

The aim of this narrative review was to explore evidence on the physiological, biochemical, and psychological effects of CBD that may be relevant to sport and/ or exercise performance and to identify relevant areas for future research. Given the absence of studies directly investigating $\mathrm{CBD}$ and sports performance, this review draws primarily on preclinical studies involving laboratory animals and a limited number of clinical trials involving non-athlete populations.

\section{Cannabidiol (CBD): Molecular Targets, Pharmacokinetics and Dosing}

\section{Molecular Targets}

The distinctive intoxicating effects of $\Delta^{9}$-THC (as well as some of its therapeutic effects) involve the activation of $\mathrm{CB}_{1} \mathrm{R}$ (the cannabinoid type 1 receptor) [12]. This ubiquitous receptor is expressed throughout the central nervous system, the peripheral nervous system, and in the cardiovascular system, gastrointestinal (GI) tract, skeletal musculature, liver, and reproductive organs [205]. Unlike $\Delta^{9}$-THC, $\mathrm{CBD}$ is not an agonist of $\mathrm{CB}_{1} \mathrm{R}$, although it may act as a negative allosteric modulator (NAM) at this site (i.e. decreasing the potency and/or efficacy of other ligands without activating the receptor itself) $[92,106]$. $\Delta^{9}$-THC also acts as an agonist at $\mathrm{CB}_{2} \mathrm{R}$ (the cannabinoid type 2 receptor) [12] and there is emerging evidence of CBD functioning as a partial agonist at this site [171]. $\mathrm{CB}_{2} \mathrm{R}$ is primarily located on immune system cells but is also expressed in the cardiovascular system, GI tract, bone, liver, adipose tissue, and reproductive organs [205]. CBD may also influence the endocannabinoid system indirectly via the inhibition of fatty acid amide hydrolase (FAAH), a key enzyme involved in the degradation of the principle endocannabinoid signalling molecule, anandamide (AEA) [92, 110]. The inhibition of FAAH is predicted to lead to an increase in brain and plasma concentrations of AEA, which acts as a partial agonist at $\mathrm{CB}_{1} \mathrm{R}$ and $\mathrm{CB}_{2} \mathrm{R}$, thereby increasing endocannabinoid tone $[92,110]$. Increases in endocannabinoid tone may also occur as a result of CBD inhibiting AEA transport via 
effects on fatty acid-binding proteins (and this mechanism may have more relevance than FAAH inhibition in humans) [57].

CBD also interacts with many other non-endocannabinoid signalling systems [92]. Briefly, at concentrations $\leq 10 \mu \mathrm{M}$, $\mathrm{CBD}$ has been reported to interact with the serotonin $1 \mathrm{~A}$ [5- $\left.\mathrm{HT}_{1 \mathrm{~A}}\right]$ receptor, the orphan $\mathrm{G}$ protein-coupled receptor 55 , as well as the glycine, opioid, and peroxisome proliferator-activated receptors, various ion channels (e.g. the transient potential vanilloid receptor type 1 channel [TRPV1] and other transient potential vanilloid channels) and various enzymes (e.g. cyclooxygenase (COX)1 and COX2, cytochrome P450 enzymes) [11, 92] (see Ibeas et al. [92] for review). CBD also possesses antioxidant properties [92].

It is important to recognise that the molecular targets of CBD are still being established, with many of those identified in in vitro cellular assays still to be validated as occurring in vivo. As such, the functional relevance of many of these interactions remains to be established.

\section{Pharmacokinetics}

CBD is often consumed orally as oil; however, it can also be ingested in other forms (e.g. gel capsules, tinctures, beverages, and confectionery products) and applied topically $[20,125]$. High concentration CBD "vape oils" (i.e. for use in e-cigarette devices) are also available in some countries, as are some CBD-dominant forms of cannabis (sometimes known as "light cannabis") that can be smoked or vaporised [20, 125]. Pure, synthetic, crystalline CBD was also vaporised in a recent laboratory study [160].

Taylor et al. [170] recently conducted a comprehensive analysis of oral CBD oil pharmacokinetics in healthy participants. When administered as a single, oral dose (1500-6000 $\mathrm{mg})$, the time to reach peak plasma concentrations $\left(t_{\text {max }}\right)$ was $\sim 4-5 \mathrm{~h}$ and the terminal half-life was $\sim 14-17 \mathrm{~h}$. Although $t_{\text {max }}$ did not increase dose-dependently in this investigation [170], another study [19], involving a much lower oral dose of CBD $(300 \mathrm{mg})$, did indicate a shorter $t_{\max }$ (i.e. $\sim 2-3 \mathrm{~h}$ ). Peak plasma concentrations $\left(C_{\max }\right)$ were $\sim 0.9-2.5 \mu \mathrm{M}$ in Taylor et al. [170], but increased $~ 4.9$-fold when CBD was administered with a high-fat meal (i.e. $\sim 5.3 \mu \mathrm{M}$ at $1500 \mathrm{mg}$ dose) [170]. Both studies observed a large amount of interindividual variation in pharmacokinetic responses $[19,170]$.

The pharmacokinetics of inhaled CBD are yet to be well characterised. However, smoked "light cannabis" (with a lower $\Delta^{9}$-THC and higher CBD content than other varieties) has been reported to elicit high serum $\mathrm{CBD}$ concentrations at $30 \mathrm{~min}$ post-treatment (that decline over time) [146]. A recent study in which participants vaporised $100 \mathrm{mg}$ of CBD likewise observed high blood CBD concentrations $30 \mathrm{~min}$ post-treatment [160]. As neither study collected blood samples within $<30$ min of CBD administration, $t_{\max }$ and $C_{\max }$ are unknown $[146,160]$.
CBD is metabolised by several cytochrome $\mathrm{P}$ [CYP] 450 enzymes (e.g. CYP3A4, CYP2C9, CYP2C19) which convert it to a number of primary and secondary metabolites (e.g. 7-OH-CBD, 6-OH-CBD, and 7-COOH-CBD) [177]. Complex pharmacokinetic interactions may occur when CBD is co-administered with other drugs (e.g. $\Delta^{9}$ THC) and dietary constituents (e.g. caffeine) that also utilise these enzymes $[6,163]$.

\section{Interspecies Dose Conversions}

Given the number of preclinical studies involving animal models that will be discussed in this review, it is important to consider interspecies dose equivalence (Table 1). The USA Food and Drug Administration [30] recommend the following approach to interspecies dose conversion:

$$
\begin{aligned}
\operatorname{HED}\left(\mathrm{mg} \cdot \mathrm{kg}^{-1}\right)= & \operatorname{Dose}_{\text {Animal }}\left(\mathrm{mg} \cdot \mathrm{kg}^{-1}\right) \\
& \times\left(\frac{\mathrm{Km}_{\text {Animal }}}{\mathrm{Km}_{\text {Human }}}\right)
\end{aligned}
$$

Where HED is the human equivalent dose and $\mathrm{Km}$ is a correction factor estimated by dividing the average body mass $(\mathrm{BM})$ of the species $(60,0.020$ and $0.150 \mathrm{~kg}$ for 11 humans, mice and rats respectively) and by its surface area (see: Nair, et al. [134] for 12 further details).

Differences between systemic and oral dosing should also be considered [9]. Intraperitoneal (i.p.) dosing is often used in animal studies and has been reported to elicit $C_{\max }$ values $\sim 7$-fold higher than oral dosing in mice [52]. Thus, an "oral equivalent dose" can be approximated by multiplying the i.p. dose by seven [9] (Table 1). Intravenous (i.v.) dosing will produce even higher plasma CBD concentrations; however, the authors are not aware of any published data that would facilitate conversion between i.v. and oral dosing in rodents. Please note that these values are intended as a guide only and subject to limitations (e.g. interspecies differences in drug potency and receptor expression/configuration).

\section{Cannabidiol (CBD) in Sport and Exercise Performance}

\section{Literature Search Methodology}

The clinical and preclinical literature was reviewed to identify studies investigating the effects of CBD that might be relevant within a sport and/or exercise context. The online databases PubMed (MEDLINE), Web of Science (via Thomas Reuters), and Scopus were searched between April and October of 2019 using terms such as: 'cannabinoid' 'cannabidiol', 'CBD' and 'cannabis'. This review focuses primarily on effects that have been demonstrated in vivo and generally avoids attempting to predict functional effects on the basis of target-oriented in vitro data, given the numerous molecular targets of 
Table 1 Oral human equivalent CBD doses from mouse and rat intraperitoneal doses

\begin{tabular}{|c|c|c|c|}
\hline \multicolumn{2}{|c|}{ Mouse to Human CBD Dose Conversion } & \multicolumn{2}{|c|}{ Rat to Human CBD Dose Conversion } \\
\hline $\begin{array}{l}\text { Mouse Dose } \\
\left(\mathrm{mg} \cdot \mathrm{kg}^{-1}, \text { i.p. }\right)\end{array}$ & $\begin{array}{l}\text { HED } \\
\text { (mg, p.o.) }\end{array}$ & $\begin{array}{l}\text { Rat Dose } \\
\left(\mathrm{mg} \cdot \mathrm{kg}^{-1} \text {, i.p.) }\right.\end{array}$ & $\begin{array}{l}\text { HED } \\
\text { (mg, p.o.) }\end{array}$ \\
\hline 1 & 34 & 1 & 68 \\
\hline 5 & 170 & 5 & 340 \\
\hline 10 & 341 & 10 & 681 \\
\hline 20 & 681 & 20 & 1362 \\
\hline 30 & 1021 & 30 & 2043 \\
\hline 60 & 2043 & 60 & 4086 \\
\hline
\end{tabular}

Each HED is based on a body mass of $60 \mathrm{~kg}$ and calculated as per the methods described in 2.3 Dose Conversions. The highest documented acute oral CBD dose in humans is $6000 \mathrm{mg}$; the highest documented chronic oral CBD dose in humans is $1500 \mathrm{mg}$ [169]. HED: Human Equivalent Dose; i.p.: Intraperitoneal; p.o.: Oral

CBD [92] and the fact that exercise itself induces complex biochemical changes. Nonetheless, some potential interactions are noted. As our intent was to summarise evidence on a range of potentially relevant topics, rather than provide a detailed assessment of the literature, the reader will be directed to more focused reviews, where appropriate. All doses described are oral and acute (single), unless otherwise stated.

\section{Exercise-Induced Muscle Damage-Muscle Function, Soreness, and Injury}

Exercise, particularly when strenuous, unfamiliar, and/or involving an eccentric component, can cause ultrastructural damage to skeletal muscle myofibrils and the surrounding extracellular matrix $[36,59]$. This exerciseinduced muscle damage (EIMD) impairs muscle function and initiates an inflammatory response [59]. While inflammation is integral to EIMD repair, regeneration, and adaptation [59], excessive inflammation may contribute to prolonged muscle soreness and delayed functional recovery $[7,158]$.

CBD modulates inflammatory processes [21]. In preclinical models of acute inflammation, CBD has been reported to attenuate immune cell accumulation (e.g. neutrophils, lymphocytes macrophages) [102, 130, 149, 186], stimulate production of anti-inflammatory cytokines (e.g. interleukin (IL)-4, IL-10) [190, 191, 23] and inhibit production of pro-inflammatory cytokines (e.g. IL-1 $\beta$, IL-6, IL-8, tumour necrosis factor (TNF)- $\alpha$ ) [10, $50,55,62,63,113,130,149,154,186]$ and reactive oxygen species [62, 130, 186]. Models demonstrating such effects have included lung injury induced by chemical treatment [149] and hypoxic-ischemia (HI) [10]; liver injury induced by ischemia-reperfusion $[63,130]$ and alcohol feeding [186]; myocardial [55] and renal [62] ischemia-reperfusion injuries; surgically induced oral lesions [102]; chemically induced osteoarthritis [145]; spinal cord contusion injury [113], and colitis [23, 50, 154] (see Burstein [24] for review). Anti-inflammatory effects are generally observed at higher CBD doses in vivo (e.g. $\geq 10 \mathrm{mg} \cdot \mathrm{kg}^{-1}$, i.p.); although, lower doses (e.g. $\sim 1.5 \mathrm{mg} \cdot \mathrm{kg}^{-1}$, i.p.) have indicated efficacy in some studies [145]. Research investigating the effects of CBD on inflammation in humans is limited and inconclusive $[94,133]$.

In terms of muscle-specific inflammation, one preclinical study has investigated the effect of high-dose CBD (i.e. $60 \mathrm{mg} \cdot \mathrm{kg}^{-1} \cdot \mathrm{d}^{-1}$, i.p.) on transcription and synthesis of pro-inflammatory markers (i.e. IL- 6 receptors, TNF- $\alpha$, TNF- $\beta 1$, and inducible nitric oxide synthase) in the gastrocnemius and diaphragm of dystrophic MDX mice (a mouse model of Duchenne muscular dystrophy) [91]. In this investigation, CBD attenuated mRNA expression of each marker and reduced plasma concentrations of IL-6 and TNF $\alpha$. Improvements in muscle strength and coordination, as well as reductions in tissue degeneration, were also reported at this dose. Lower, but still relatively high, CBD doses $\left(20-40 \mathrm{mg} \cdot \mathrm{kg}^{-1} \cdot \mathrm{day}^{-1}\right.$, i.p.) had no functional benefits [91]. Of course, it is important to recognise that EIMD and muscular dystrophy differ in their pathophysiology, and so the effects observed in MDX mice may involve mechanisms less relevant to EIMD (e.g. skeletal muscle differentiation, autophagy) [91].

While CBD could potentially aid in muscle recovery, other anti-inflammatory agents, such as ibuprofen (a non-steroidal anti-inflammatory drug [NSAID]) have been reported to attenuate exercise-induced skeletal muscle adaptation [120]. The precise mechanism(s) underpinning these effects have not been fully elucidated, although it may be that the prevention of inflammation inhibits angiogenesis and skeletal muscle hypertrophy [120]. Human trials also suggest that ibuprofen may not influence EIMD, inflammation, or soreness $[144,175]$. Thus, if CBD exerts its effects via similar mechanisms, it could possibly attenuate the benefits of training without influencing muscle function or soreness. Future studies investigating this are clearly warranted to clarify such issues and elucidate the potential benefits of CBD. 


\section{Neuroprotection-Concussion and Subconcussion}

Recent estimates suggest that $6-36 \%$ of high school and collegiate athletes in the USA have experienced more than one concussion [72], potentially predisposing them to long-term neurodegenerative diseases [72] and an increased risk of suicide [64]. Concussion is a distinct form of mild traumatic brain injury (TBI) in which a biomechanical force temporarily disrupts normal brain functioning causing neurological-cognitive-behavioural signs and symptoms [97]. Similar injuries that do not produce overt (acute) signs or symptoms are termed "subconcussions" [97]. In TBI, the primary injury occurs as a result of the biomechanical force; secondary injury is then sustained through a complex cascade of events, including $\mathrm{HI}$, cerebral oedema, increased intracranial pressure, and hydrocephalus [203]. These processes are, in turn, related to a number of detrimental neurochemical changes, including glutamate excitotoxicity, perturbation of cellular calcium homeostasis, excessive membrane depolarisation, mitochondrial dysfunction, inflammation, increased free radicals and lipid peroxidation, and apoptosis [203]. While the primary injury may not be treatable, interventions that attenuate secondary sequelae are likely to be of benefit [203].

Only one study [14] has investigated the biochemical and neuropsychological effects of CBD in an animal model of TBI. Here, C57BL/6 mice were given chronic CBD treatment ( $3 \mu \mathrm{g} \cdot \mathrm{day}^{-1}$, oral) $1-14$ and 50-60 days post- (weight drop) brain insult. CBD attenuated the behavioural (e.g. anxious and aggressive behaviour, depressive-like behaviour, impaired social interactions, pain-related behaviours) and some of the cortical biochemical abnormalities were observed. Specifically, CBD tended to normalise extracellular glutamate, D-aspartate, and $\gamma$-aminobutyric acid concentrations in the medial prefrontal cortex, suggesting a reduction in excitotoxicity. However, neuronal damage was not measured directly in this study [14].

Other preclinical studies have investigated the impact of CBD on different animal models of acute neuronal injury, in particular, acute cerebral $\mathrm{HI}[4,13,31,68,69$, $80,81,83,100,105,127,129,142,143,153]$. Studies administering a single (acute) dose of CBD shortly post-HI (e.g. $\leq 1 \mathrm{~h}$ ) have produced inconsistent results. For instance, while Garberg et al. [68, 69] found no effect of CBD (1 or $50 \mathrm{mg} \cdot \mathrm{kg}^{-1}$, i.v.) on $\mathrm{HI}$-induced neuronal damage in piglets, others observed neuroprotection at similar doses (e.g. $1 \mathrm{mg} \cdot \mathrm{kg}^{-1}$, i.v $[105,143] ., 1 \mathrm{mg} \cdot \mathrm{kg}^{-1}$, s.c [127, 142]., and $5 \mathrm{mg} \cdot \mathrm{kg}^{-1}$, i.p [31].) in piglets and rats. When given chronically, or repeatedly within a short timeframe proximal to the HI event, however, CBD appears to be neuroprotective. Effective dosing strategies have varied and included initiating treatment several days pre-HI (e.g. 100 or $200 \mu$ g.day $^{-1}$, intracerebroventricular 5 days; Wistar rats [100]), shortly pre- and/or post- $\mathrm{HI}^{1}$, and up to 3 days post-HI (e.g. 3 $\mathrm{mg} \cdot \mathrm{kg}^{-1} \cdot \mathrm{day}^{-1}$, i.p. 12 days; ddY mice [80]). Thus, chronic CBD treatment may be more effective than acute intervention. While "pre-incident" dosing might also be beneficial, it is noted that in practice, this would require humans at risk of TBI to use CBD chronically as a prophylactic.

The precise mechanism(s) underpinning the neuroprotective effects of CBD are not completely understood (see Campos et al. [25] for review), but may involve decreased inflammation, oxidative stress, and excitotoxicity [142, 143] and increased neurogenesis [129]. Preclinical studies have also demonstrated beneficial effects of CBD in other animal models of neurodegeneration (e.g. transgenic model of Alzheimer's disease [34, 35], brain ironoverload $[47,48])$. Collectively, these data suggest that research investigating the utility of CBD in ameliorating the harmful long-term effects of repeated sports concussions is warranted.

\section{Nociceptive and Neuropathic Pain}

Persistent pain is common in athletes [74]. Nociceptive pain, which includes inflammatory pain, typically occurs with tissue damage; whereas neuropathic pain typically results from a lesion or disease in the somatosensory nervous system [74]. Neuropathic pain is common among para-athletes with spinal cord injuries and can also arise with surgery (e.g. to treat an existing injury) or if there is repetitive mechanical and/or inflammatory irritation of peripheral nerves (e.g. as in endurance sports) [74].

Clinical trials investigating the combined effects of $\Delta^{9}$ THC and CBD (e.g. Sativex ${ }^{\circ}$ ) on chronic neuropathic pain have yielded promising initial results $[87,114,151$, 156]. However, the therapeutic effects of CBD administered alone have received limited clinical attention. Preclinical (in vivo) studies investigating the effects of CBD on neuropathic and nociceptive pain are summarised in Table 2. Despite some methodological inconsistencies (e.g. the pain model, period of treatment, route of delivery), most preclinical studies appear to have observed a significant analgesic effect of CBD [29, 39-41, 51, 70, 75, 78], albeit somewhat less pronounced than the effects of $\Delta^{9}$-THC [29, 78] (e.g. Hedges' $g=0.8$ vs. 1.8 [78]) or of gabapentin (e.g. Hedges' $g=2.0$ [78]), a commonly used agent for treating neuropathic pain. Capsazepine cotreatment has also been reported to attenuate CBDinduced analgesia, suggesting that the effect may be mediated, at least in part, by the $\mathrm{TRPV}_{1}$ channel [40, 41, 51]. This mechanism is noteworthy as studies have

${ }^{1}$ E.g. $10-30 \mathrm{mg} \cdot \mathrm{kg}^{-1} \cdot$ day $^{-1}$, i.p. 3 days $[129,153], 1 \mathrm{mg} \cdot \mathrm{kg}^{-1} \cdot$ day $^{-1}$, i.v. 3 days [13], $1-3 \mathrm{mg} \cdot \mathrm{kg}^{-1}$, i.p. pre- and $3 \mathrm{~h}$ post-HI $[81,83$ ] or 0.1 $\mathrm{mg} \cdot \mathrm{kg}^{-1}$, i.v. 15 and $240 \mathrm{~min}$ post-HI [4]. 


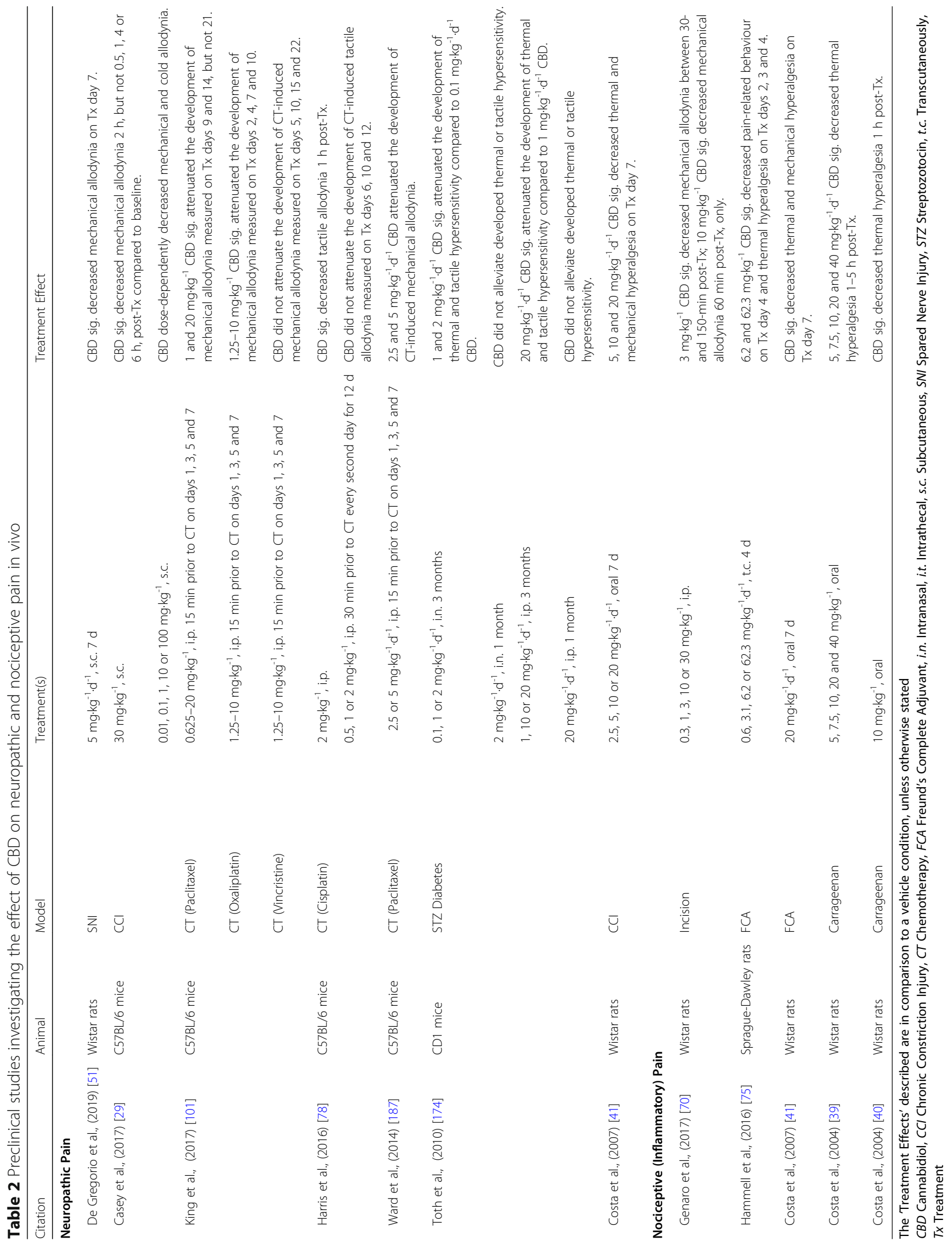


implicated the TRPV ${ }_{1}$ in the development of mechanical hyperalgesia induced by muscle inflammation $[66,140]$.

It is important to recognise that the analgesic effect of CBD likely depends on several factors, including the treatment dose and the type of pain involved. Indeed, low doses of CBD (e.g. $\leq 1 \mathrm{mg} \cdot \mathrm{kg}^{-1}$, i.p.) do not consistently attenuate pain $[29,41,70,75,101]$; while higher doses are sometimes found to be more [29], and other times, less [70], efficacious than moderate doses in preclinical studies (Table 3). This highlights the importance of determining a therapeutic dose for CBD in analgesia. Data from King et al. [101] also demonstrate the selectivity of the response, indicating that CBD only effective in attenuating the development of neuropathic pain induced by certain chemotherapeutic agents (i.e. paclitaxel and oxaliplatin but not vincristine). Thus, placebocontrolled trials of CBD in treating pain in clinical populations and athletes are warranted.

\section{Exercise-Induced Gastrointestinal (GI) Damage}

While strenuous exercise increases blood supply to the active skeletal muscles, cardiopulmonary system and skin-other organs and tissues, including the GI tract, experience reduced oxygen and nutrient delivery [180]. If exercise is prolonged (e.g. $>40 \mathrm{~min}$ ), this "GI ischemia", as well as the inflammation and oxidative stress that accompanies reperfusion, can compromise epithelial integrity [180]. Such effects may negatively influence exercise performance and post-exercise recovery due to GI distress (e.g. nausea, vomiting, abdominal angina, bloody diarrhoea) and impaired nutritional uptake [180].

CBD has demonstrated some effects that may be relevant to the management of exercise-induced GI damage. For instance, preclinical studies have shown that CBD (e.g. $0.01-10 \mathrm{mg} \cdot \mathrm{kg}^{-1}$, i.v. or $10 \mathrm{mg} \cdot \mathrm{kg}^{-1}$, i.p.) can attenuate tissue damage (e.g. reduce necrosis, blood concentrations of tissue damage markers and inflammation) induced by acute, peripheral ischemia-reperfusion (e.g. kidney, myocardium, liver) [55, 60, 62, 63, 130, 185] and colitis $[23,50,154]$ in vivo; benefits that have generally been attributed to its reported antioxidant and antiinflammatory effects (see also section "Exercise-Induced Muscle Damage-Muscle Function, Soreness, and Injury") [50, 55, 60, 62, 63, 130, 154, 185]. Also, of interest is that CBD $(1-100 \mu \mathrm{M})$ has been reported to restore intestinal permeability in vitro following exposure to Clostridium difficile toxin $A$, ethylenediaminetetraacetic acid and pro-inflammatory stimuli (e.g. interferon-gamma, TNF- $\alpha)[2,3,71]$.

Of course, it is important to recognise that evidence to support a therapeutic effect of CBD on GI damage in humans is currently lacking. In fact, two placebocontrolled, double-blinded clinical trials, one investigating the effect of CBD (10 $\mathrm{mg}^{-1} \mathrm{~d}^{-1} 56$ days) on symptom severity in Crohn's disease $(n=20)$ [133] and the other examining the impact of a "CBD-rich botanical extract" $\left(250 \mathrm{mg} \cdot\right.$ day $^{-1}$ [4.7\% THC]; $56 \mathrm{~d}$ ) on the likelihood of remission in ulcerative colitis $(n=60)$ [94], have so far been unable to demonstrate a protective effect of CBD (above placebo) on disease markers, including C-reactive protein, faecal calprotectin, and pro-inflammatory cytokines (e.g. IL-2, IL-6, TNF- $\alpha$ ).

While CBD could potentially attenuate exercise-induced GI damage, it is important to note that other antiinflammatory agents, such as the NSAID, ibuprofen, have been reported to exacerbate exercise-induced GI damage and impair gut barrier function [181]. The precise mechanism(s) underpinning these effects have not been fully elucidated. However, NSAIDs have been suggested to augment GI ischemia by inhibiting the COX1 and COX2 enzymes and interfering with nitric oxide production [180]. Some in vitro research similarly suggests that CBD partially inhibits COX1 and COX2, although this effect has only been reported at supraphysiological concentrations (e.g. 50-500 $\mu \mathrm{M}$ CBD) [92]. Thus, the effect of CBD on exercise-induced GI damage warrants clarification.

\section{Bone Health}

While the beneficial effects of high-impact exercise on bone health are well established [38], other factors within the sporting context (e.g. traumatic injuries, low energy availability [117]) may cause or contribute to reduced bone health and the development of fractures in athletes.

A small number of preclinical studies have investigated the effects of CBD on bone structure and function [103, $112,135]$. While most have used animal models that are limited in their direct relevance to sport and/or exercise performance (e.g. periodontitis, systemic skeletal degeneration due to spinal cord injury) one investigation [103] did report that CBD improved the healing of femoral fractures in Sprague-Dawley rats. Specifically, chronic CBD treatment (i.e. $5 \mathrm{mg} \cdot \mathrm{kg}^{-1} \cdot$ day $^{-1}$, i.p.) decreased callus size 4-weeks post-fracture and enhanced the biomechanical properties of the bone at 8-weeks (i.e. maximal force, work-to-failure on a 4-point bending test) [103]. While the mechanism(s) underlying this effect require clarification, CBD may act to inhibit expression of RANK and RANK-L (i.e. indicative of an effect to suppress osteoclastogenesis, and thus, bone resorption) and decrease the production of pro-inflammatory cytokines (e.g. IL-1 $\beta$, TNF- $\alpha$ ) at the site of injury $[103,135]$. Evidence that activation of $\mathrm{CB}_{2} \mathrm{R}$ induces bone matrix deposition has also recently emerged [150] alongside data suggesting that CBD may have partial agonist effects at this site [171]. These initial findings suggest that further research investigating the effect of CBD on acute skeletal injuries is worthwhile. 


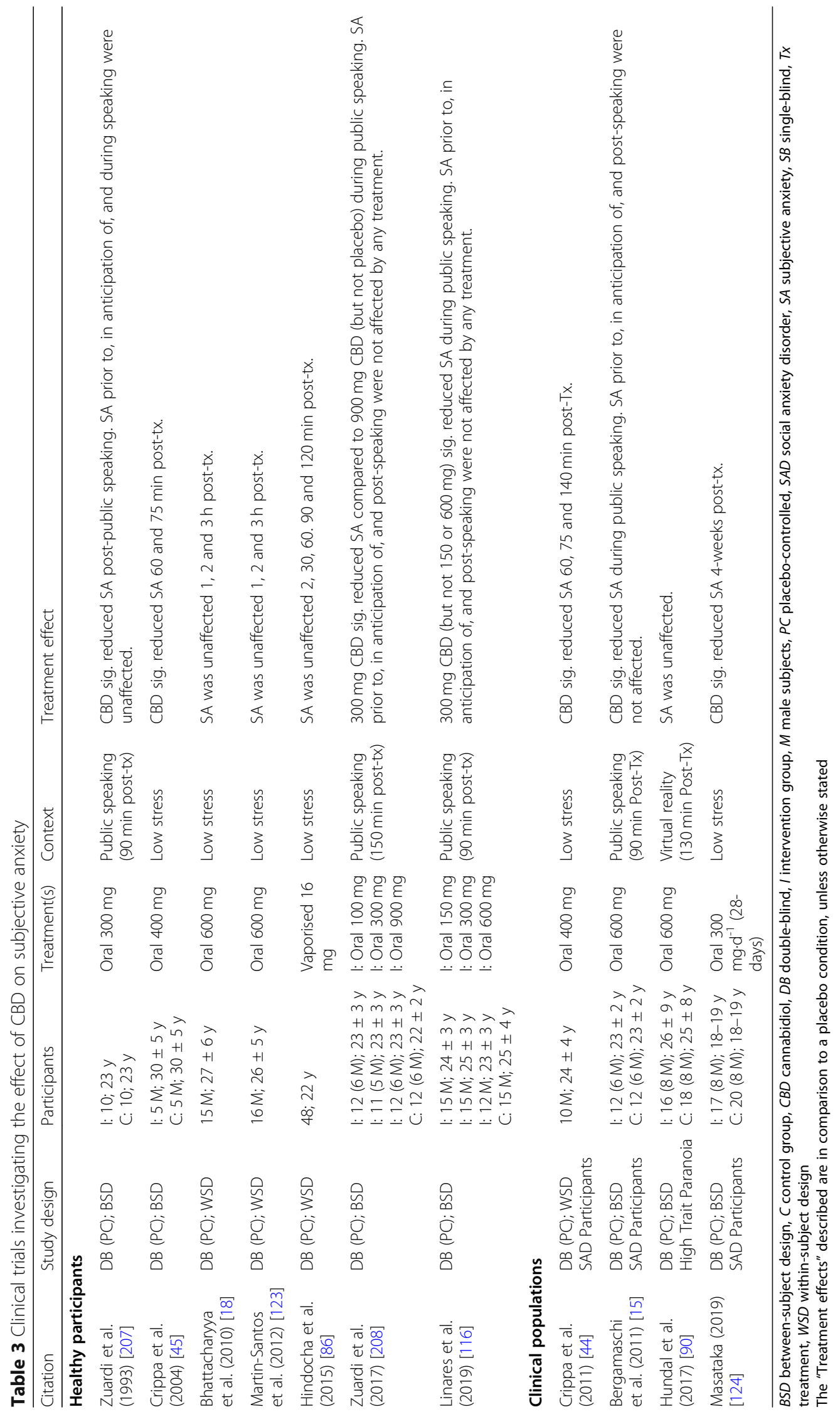




\section{Cardiovascular (CV) and Metabolic Functions}

A number of studies have measured $\mathrm{CV}$ responses to CBD (100-1200 mg) in humans and, overall, it appears that resting HR is unaffected (see Sultan et al. [165] for review). However, some evidence does suggest that $\mathrm{CBD}$ (600 mg) reduces resting systolic BP (e.g. $-6 \mathrm{mmHg}$ ) [95, 164]. Preclinical studies have likewise shown that CBD influences vascular function [139, 161, 162, 193, 194]. Briefly, in vitro CBD treatment (i.e. $\leq 2 \mathrm{~h}$ exposure to $1-$ $10 \mu \mathrm{M})$ has been reported to induce vasorelaxation [139] and potentiate vasorelaxation to acetylcholine $[162,193]$ in isolated (pre-constricted) arteries of rats [139, 162, 193]. A recent study [161] also found that in vitro CBD treatment (i.e. $\leq 2 \mathrm{~h}$ exposure to $10 \mu \mathrm{M}$ ) induced $\sim 40 \%$ vasorelaxation in isolated (pre-constricted) mesenteric arteries of humans with various clinical conditions (e.g. cancer, inflammatory bowel disease, type $\mathrm{Z}$ diabetes mellitus [T2DM]).

In addition to "resting" CV parameters, a recent metaanalysis (of largely preclinical studies) found that CBD attenuated "stress-induced" (e.g. via fear-conditioning or physical-restraint) increases in $\mathrm{HR}$ and $\mathrm{BP}$ (BP -3.5 mmHg; 95\% CI $-5.2,-1.9 ; I^{2}=73 \%$; HR -16 mmHg; 95\% CI $-26,-6 ; I^{2}=92 \%$ ) [165], that said, most studies measuring CV responses to CBD (150-600 mg) under "stress-inducing" conditions in humans (e.g. public speaking) find no effect on $\mathrm{HR}$ or BP $[15,116,207]$. One placebo-controlled, double-blinded (single-dose) crossover trial of healthy males $(n=9)$ [95] did report that CBD $(600 \mathrm{mg})$ increased HR in the presence of certain stressors (i.e. a mental arithmetic test, an isometric contraction on a hand-grip dynamometer, and cold exposure); and, at times, reduced systolic and diastolic BP. However, these differences were apparent at baseline (pre-stress) and the data were not standardised to account for this, making interpretation difficult.

Taken together, these findings suggest that CBD has the potential to influence $\mathrm{CV}$ function. However, the implications of these effects in regard to exercise performance are unclear. Studies investigating the effect of CBD on exercise-induced $\mathrm{CV}$ responses are therefore required to clarify its utility within the sport and exercise context.

One final observation to note is that some initial data suggest $\mathrm{CBD}$ might influence mitochondrial function. Indeed, in vivo CBD treatment has been reported to increase the activity of mitochondrial complexes [48, 77, 130, 178] (30-60 mg.kg- ${ }^{1}$, i.p. acute or chronic 14 days Wistar rats; 3 and $10 \mathrm{mg} \cdot \mathrm{kg}^{-1}$, i.v. C57BL/6 J mice; 10 $\mathrm{mg} \cdot \mathrm{kg}^{-1} \cdot \mathrm{day}^{-1}$, i.p. 5 days $\mathrm{C} 57 \mathrm{BL} / 6 \mathrm{~J}$ mice; and 10 $\mathrm{mg} \cdot \mathrm{kg}^{-1} \cdot \mathrm{day}^{-1}$, i.p. 14 days Wistar rats) in various tissues and models (i.e. healthy brain, myocardium following doxorubicin treatment, brain following neonatal ironoverload, hepatic ischemia-reperfusion injury) and increase mitochondrial biogenesis [77] $\left(10 \mathrm{mg} \cdot \mathrm{kg}^{-1} \cdot \mathrm{day}^{-1}\right.$, i.p. 5 days C57BL/6 J mice; myocardium following doxorubicin treatment). Such effects could have implications for energy metabolism during exercise.

\section{Thermoregulation}

Heat loss mechanisms play a pivotal role in the maintenance of homeostasis during exercise; any treatment or condition that alters core body temperature $\left(\mathrm{T}_{\mathrm{C}}\right)$, therefore has the potential to impact exercise performance [192]. The effect of CBD on $\mathrm{T}_{\mathrm{C}}$ has been investigated in rodents $[65,82,83,85,96,118,166,182]$. The most recently published study found that CBD $\left(100 \mathrm{mg} \cdot \mathrm{mL}^{-1}\right.$, 30 min vaporised; Wistar rats) reduced $\mathrm{T}_{\mathrm{C}}\left(-1.0^{\circ} \mathrm{C}\right) 60$ and $90 \mathrm{~min}$ following inhalation in resting animals [96]. In contrast, Long et al. [118] reported a hyperthermic effect $\left(+2.0^{\circ} \mathrm{C}\right) 30 \mathrm{~min}$ post-treatment $\left(1\right.$ and $10 \mathrm{mg} \cdot \mathrm{kg}^{-1}$, i.p.; C57BL/6JArc mice) during a chronic-dosing experiment, although, this response was only observed intermittently during a 21 -day protocol (e.g. $\sim 8 \%$ of total measurements). The fact that $\mathrm{CBD}$ affected $\mathrm{T}_{\mathrm{C}}$ in these experiments is difficult to explain, since although other cannabinoids (e.g. $\Delta^{9}$-THC, AEA) have demonstrated a capacity to moderate $\mathrm{T}_{\mathrm{C}}$ when administered exogenously (e.g. low doses of $\Delta^{9}$-THC may sometimes induce hyperthermia $[168]$ and high doses cause hypothermia $[65,82$, $83,85,96,118,166,182])$, these effects occur via a $\mathrm{CB}_{1} \mathrm{R}$-mediated mechanism $[42,166,196]$. In addition to this, no other studies appear to have detected changes in $\mathrm{T}_{\mathrm{C}}$ with $\mathrm{CBD}$ administration $[65,82,83,85,166,182]$.

Overall, despite some inconsistencies, the available data suggest that CBD is unlikely to have a major influence on $T_{C}$ or thermoregulatory processes. In any case, it seems that with the exception of self-reported feelings of "coldness" [33, 88], exogenous cannabinoids do not typically induce the same overt, significant effects on $T_{C}$ in humans $[104,183]$ as are seen in rodents. Still, it should be acknowledged that the thermoregulatory response to heat stress (i.e. passive or metabolic), specifically, has not been studied.

\section{Dietary Intake and Feeding}

An adequate intake of energy and nutrients is essential to support optimal athletic training, recovery, and performance [173]. Various preclinical studies have investigated the effect of CBD on feeding behaviour in rodents [58, 93, 155, 159, 195], with results suggesting that higher doses may influence food intake several hours post-treatment. Indeed, while $\mathrm{CBD}$, at doses of 3-100 $\mathrm{mg} \cdot \mathrm{kg}^{-1}$, i.p. (IRC mice) [195] and $1-20 \mathrm{mg} \cdot \mathrm{kg}^{-1}$, i.p. (Wistar rats) [155], failed to influence food intake during a $1 \mathrm{~h}$ ad libitum feeding period, moderate to high doses of CBD (4.4 mg. $\mathrm{kg}^{-1}$, i.p. [58]. and $50 \mathrm{mg} \cdot \mathrm{kg}^{-1}$, i.p. [159]) suppressed food intake (in rats) during longer ad libitum feeding periods (i.e. $4-6 \mathrm{~h}$ ). In line with these results, 
Ignatowska-Jankowska et al. [93] found that chronic CBD treatment (2.5 and $5 \mathrm{mg} \cdot \mathrm{kg}^{-1} \cdot$ day $^{-1}$, i.p. 14 days) attenuated BM gains in growing Wistar rats. A recent systematic review of human trials also reported that individuals with epilepsy receiving CBD (5-20 $\mathrm{mg} \cdot \mathrm{kg}^{-1} \cdot \mathrm{day}^{-1}$ ) were more likely to experience decreased appetite than those receiving placebo (i.e. 20 vs. $5 \%$ of patients) [107].

That said, a mechanistic understanding of these effects of $\mathrm{CBD}$ on feeding behaviour remains to be established. Other cannabinoids with $\mathrm{CB}_{1} \mathrm{R}$ agonist effects (e.g. $\Delta^{9}$ THC, AEA, cannabinol) reliably induce hyperphagia when administered exogenously [58, 197, 198]; but CBD lacks such an effect. Ignatowska-Jankowska et al. [93] did report that the selective $\mathrm{CB}_{2} \mathrm{R}$ antagonist, $\mathrm{AM} 630$, prevented $\mathrm{CBD}$-induced $\mathrm{BM}$ changes; however, $\mathrm{CB}_{2} \mathrm{R}$ has not generally been linked to feeding behaviour, and if $\mathrm{CBD}$ is indirectly increasing endocannabinoid tone (i.e. via AEA) [92], this might be expected to promote feeding behaviour (via indirect $\mathrm{CB}_{1} \mathrm{R}$ agonist effects) [197]. A role for GI side effects in affecting appetite therefore cannot be ruled out [107]. Further preclinical research appears to be required to clarify the mechanisms underlying these functional effects on feeding. Controlled trials are also needed to determine whether CBD influences appetite and dietary behaviour in humans, particularly during the pre- and post-exercise period, where nutrient provision is critical.

\section{Illness and Infection}

Some research suggests that athletes experience a decrease in immunity and are at increased risk of developing acute illnesses (particularly upper respiratory tract infections) during periods of heavy training and competition [184]. This phenomenon has been attributed to various factors such as increased psychological stress, poor sleep, long-haul travel, exposure to extreme environments (e.g. altitude), and low energy availability [184]. A recent review of online content identified a number of webpages claiming benefits of using CBD for the treatment of viral illnesses, including cold and flu [167]. However, research supporting such "protective effects" of CBD is extremely limited. In fact, the authors identified only two (in vitro) studies reporting antimicrobial effects [5, 179] and two (in vitro) studies reporting anti-viral effects $[119,122]$ (see Tagne et al. [167] and Nichols et al. [136] for reviews). In the former, CBD demonstrated anti-microbial activity against various strains of Staphylococcus aureus [5, 179], as well as Staphylococcus pyogenes, Staphylococcus milleri, and Staphylococcus faecalis [179] at minimum concentrations of $\sim 3.2-15.9 \mu \mathrm{M}$; however, one study also found that these effects were virtually abolished when the original media (a nutrient broth agar) was replaced with one containing 5\% blood (increasing the minimum concentration to $\sim 160 \mu \mathrm{M}$ CBD) [179]. In the latter, CBD indicated anti-viral activity against the hepatitis $\mathrm{C}$ virus $\left(\mathrm{EC}_{50}=3.2 \mu \mathrm{M}\right)$ and the Kaposi's sarcoma-associated herpesvirus $\left(\mathrm{EC}_{50}=2.1 \mu \mathrm{M}\right)$, but not the hepatitis $\mathrm{B}$ virus [119, 122]. While these findings hint at some promise, others caution that CBD could potentially weaken host defence against invading pathogens because of its tendency to modify the function of various immune cells (see also section "Exercise-Induced Muscle Damage-Muscle Function, Soreness, and Injury") [136, 147]. Importantly, a systematic review of studies investigating the safety of CBD in individuals with intractable epilepsy found that upper respiratory tract infections were similarly infrequent in participants who received the active treatment $\left(5-20 \mathrm{mg} \cdot \mathrm{kg}^{-1} \cdot \mathrm{day}^{-1}\right)$ and placebo (approx. 10\% of individuals) [107]. Further research to develop a better understanding of "if" and "how" CBD influences the development and progression of illness and infection in both athlete and non-athlete populations would be useful.

\section{Sports Performance Anxiety (SPA)}

High levels of pre-competition stress, or sports performance anxiety (SPA) [141], can be detrimental to athletic performance [43]. This impairment has been attributed to both the direct (i.e. anxiogenic) and indirect (e.g. decreased nutritional intake, increased energy expenditure, loss of sleep) effects of SPA [28]. While behaviour therapies (e.g. cognitive behavioural therapy) are the preferred treatment, a combination of pharmaceutical and psychological interventions may be indicated in some cases [141].

A number of (small) clinical trials have investigated the effect of CBD on subjective anxiety in healthy individuals $[18,45,86,116,123,207,208]$ and in individuals with social anxiety disorder (SAD) $[15,44,124]$ and high trait paranoia [90] under both standard (i.e. "low stress") $[18,44,45,86,123,124]$ and "stress-inducing" (e.g. simulated public speaking) $[15,90,116,207,208]$ conditions (Table 3). Overall, results suggest that CBD has little influence on anxiety under "low stress" conditions in healthy participants $[18,86,123]$. However, several studies have demonstrated anxiolytic effects of CBD (300$600 \mathrm{mg}$ ) under "stress-inducing" conditions in both healthy participants and those with SAD $[15,44,116$, 124, 207]. In fact, CBD (300 mg) had comparable efficacy to the anxiolytic $5-\mathrm{HT}_{1 \mathrm{~A}}$ agonist drug, ipsapirone (5 mg), during a simulated public speaking test in one study [207]. On the other hand, some other clinical investigations (involving similar "stress-inducing" stimuli) have found no effect of CBD [90, 208] and Hundal et al. [90] observed a non-significant trend $(p<0.10)$ towards an anxiogenic effect with $600 \mathrm{mg} \mathrm{CBD}$ in a high trait 
paranoid group $(n=32)$. Inconsistencies could be due to inter-individual differences in baseline anxiety levels and the magnitude of the stress-response to the stressor imposed, small sample sizes, and differences in the dose and formulation of CBD provided. Indeed, Linares et al. [116] observed an inverted U-shaped dose-response relationship between acute CBD treatment and subjective anxiety, indicating that $300 \mathrm{mg}$ (Hedges' $g=1.0$ ) had a stronger anxiolytic effect than $150 \mathrm{mg}$ (Hedges' $g=0.7$ ) or $600 \mathrm{mg}$ (Hedges' $g=0.6$ ).

Taken together, it appears that moderate doses of CBD may be anxiolytic in stressful situations and in individuals with SAD. Thus, studies investigating the effect of CBD (in conjunction with behaviour therapies) on pre-competition anxiety, as well as nutritional intake, energy expenditure, symptom perception during exercise (e.g. ratings of perceived exertion), and sleep in athletes who are negatively impacted by SPA are warranted.

\section{Sleep}

The importance of adequate sleep in facilitating optimal athletic performance and recovery is increasingly recognised [121]. Yet, athletes often sleep less (e.g. 6.5-6.7 $h \cdot$ night $^{-1}$ ) and experience poorer quality sleep than nonathletes [79, 109, 152]. Factors that contribute to poor sleep among athletes include evening competitions and training sessions, pre-competition anxiety, use of caffeine, and long-haul travel (e.g. jet lag, travel fatigue) [121].

Several studies have investigated the effect of CBD on sleep in humans $[26,32,115,157]$. The first placebocontrolled, double-blinded (single-dose) crossover trial [26] found that $160 \mathrm{mg}$ CBD (but not 40 or $80 \mathrm{mg}$ ) increased self-reported sleep duration in individuals with insomnia $(n=15)$; although time to sleep onset, number of sleep interruptions, and likelihood of experiencing "good sleep" were unchanged. Two case studies also indicated the benefits of CBD [32, 157]. Specifically, Chagas et al. [32] observed a reduction in symptoms of rapid eye movement sleep-behaviour disorder in four individuals with Parkinson's disease (75-300 mg.day ${ }^{-1}$; 42 day) and Shannon et al. [157] found that CBD $\left(\sim 25{\left.\mathrm{mg} \cdot \text { day }^{-1}\right)}^{-1}\right.$ improved subjective sleep quality in a young girl with post-traumatic stress disorder (PTSD). Of course, these studies $[26,32,157]$ are limited in that they rely on subjective measures of sleep and involve small sample sizes; the improvements observed could also be due to CBD attenuating other sleep-impairing comorbid conditions (e.g. anxiety, PTSD). Indeed, a recent placebo-controlled, double-blinded (single-dose) crossover trial [115] found no effect of CBD $(300 \mathrm{mg})$ on sleep architecture measured via polysomnography in healthy adults $(n=27)$.

While CBD seems unlikely to directly influence sleep in healthy humans [115] (and may be "sleep-promoting" in those with certain comorbid conditions) [26, 32, 157], a small number of rodent studies suggest that the cannabinoid could actually be "wake-inducing" [128, 132, 204]. One placebo-controlled, double-blinded (single-dose) crossover trial of healthy individuals $(n=8)$ [137] also found that low-dose CBD (15 mg) counteracted some of the sedative effects of co-administered $\Delta^{9}$-THC $(15 \mathrm{mg})$, i.e. increasing overnight wakefulness; although, this effect could be due to CBD acting as a NAM of $C_{1} R$, thereby attenuating $\Delta^{9}$-THCs effects on that receptor [92]. Differences in the doses of CBD administered might partly explain this inconsistency. Indeed, Monti [128] observed a biphasic effect of CBD on sleep in Wistar rats, such that a lower dose decreased, and a higher dose increased (20 vs. $40 \mathrm{mg} \cdot \mathrm{kg}^{-1}$, i.p.), slow-wave sleep latency. However, inter-species differences are also a consideration as nocturnal animals appear to exhibit different circadian patterns of endocannabinoid signaling compared to humans [84, 131]. Collectively, the current evidence on CBD and sleep endorses the need for further research in clinical populations and athletes.

\section{Cognitive and Psychomotor Function}

A small number of clinical trials have investigated the effects of CBD on cognitive and psychomotor function in healthy individuals (Table 4). Overall, results suggest a minimal influence of CBD on cognitive or psychomotor function. While one early investigation [98] reported that CBD (15 or $60 \mathrm{mg}$ ) caused participants to under-/over-estimate the duration of a 60-s interval on several occasions throughout a repetitive testing protocol (i.e. as is indicative of impaired concentration), the magnitude of error was small (e.g. $<5 \mathrm{~s}$; particularly, in comparison to that observed with $\Delta^{9}$-THC, e.g. $\sim 10-25 \mathrm{~s}$ [98]) and the effect was inconsistent, suggesting it may be an artefact of the between-subject design and small sample size. A more recent investigation [86] observed an improvement in emotion recognition with CBD (16 mg vaporised); however, this "ability" may have limited relevance to the sporting context. More applicable, perhaps, is Dalton et al. [49] finding no effect of CBD (150 $\mu \mathrm{g} \cdot \mathrm{kg}^{-1}$ vaporised) on balance or coordination (a product of both cognitive and motor function). A more recent investigation likewise found no effect of oral or vaporised CBD $(100 \mathrm{mg})$ on cognitive performance between $30 \mathrm{~min}$ and $8 \mathrm{~h}$ posttreatment [160] (Table 4). Thus, while only a narrow range of doses and relatively few discrete cognitive functions have been studied, the available data suggest that $\mathrm{CBD}$ is unlikely to impact cognitive or psychomotor function on healthy individuals.

\section{Other Considerations CBD "Nutraceutical” Products}

Over-the-counter CBD-containing "nutraceuticals" are now readily available in many countries and of increasing 


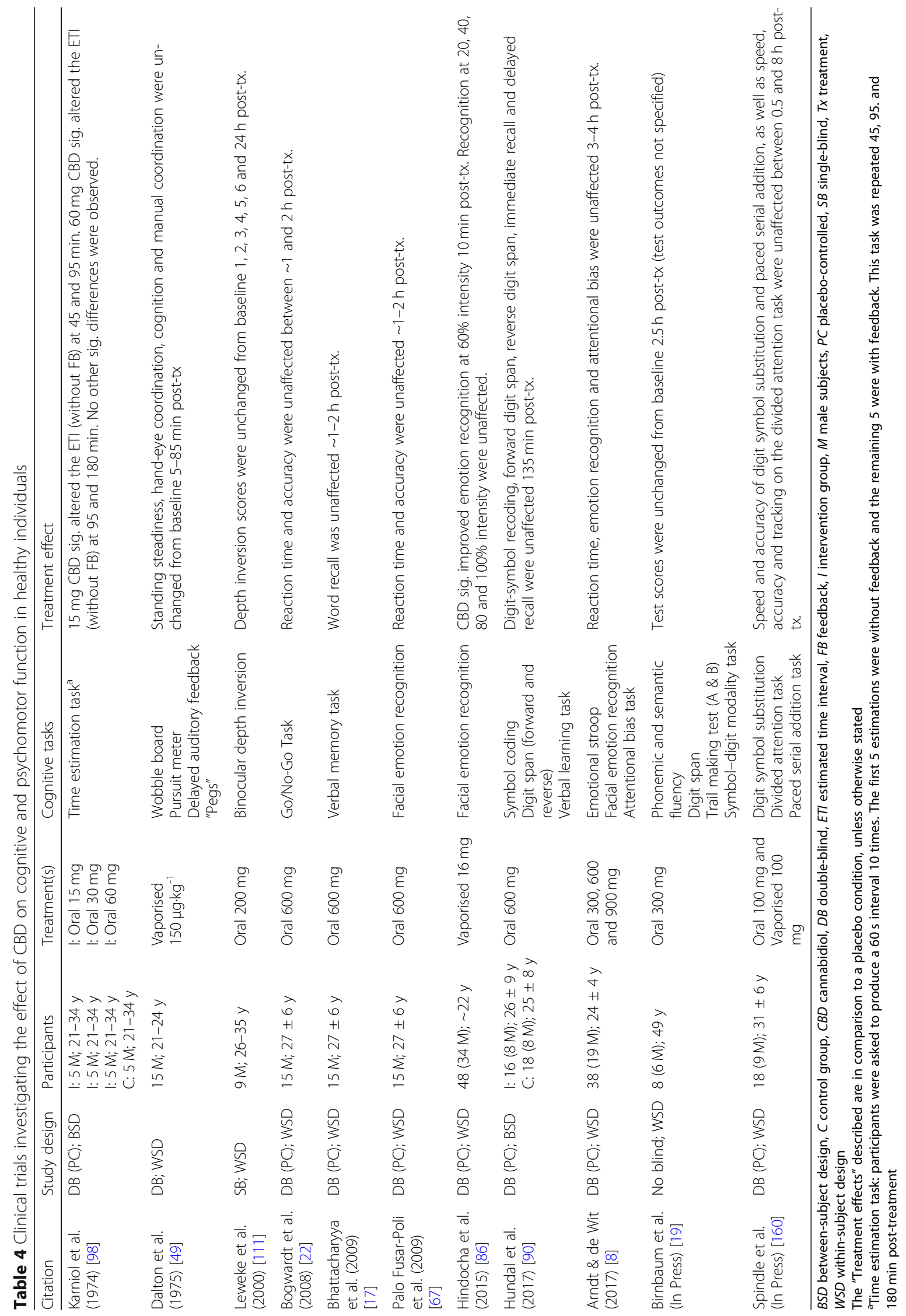


interest to the community [108]. However, it is important to be aware that these products are often limited in that they typically contain low levels of CBD (e.g. 10-50 $\mathrm{mg} \cdot \mathrm{mL}^{-1}$ ), [20] making it difficult to achieve the higher doses often used in the studies described in this review.

Additionally, over-the-counter CBD nutraceuticals are not always manufactured to the same pharmaceutical standards as regulated, prescription CBD products (e.g. Epidiolex ${ }^{\circ}$ ). Indeed, a recent study [20] reported that only $\sim 31 \%$ of CBD extracts sold online $(n=84)$ were "labelled accurately" (i.e. a measured CBD content within $10 \%$ of the labelled value); nearly half underestimated, and a quarter overestimated, their CBD content-approximately one-fifth of samples also contained detectable levels of $\Delta^{9}$ THC. A similar investigation [148] of nine CBD "e-liquids" (used for vaporising) found that two contained $\Delta^{9}$ THC, four contained 5-fluoro MDMB-PINACA (a potent synthetic cannabinoid receptor agonist with powerful psychoactive effects), and one contained dextromethorphan. Thus, individuals using these products are at risk of over-/ under-dosing, adverse health effects and/or possibly, recording a positive drug test result. This suggests that until such time as better manufacturing standards are imposed, athletes in competition might wish to avoid using nonregulated CBD-containing nutraceuticals, or, at least carefully investigating their quality control and provenance before using them.

\section{Conversion of CBD to $\Delta^{9}-\mathrm{THC}$}

In vitro studies have shown that $\mathrm{CBD}$ can undergo conversion to $\Delta^{9}$-THC with prolonged exposure to simulated gastric fluid [126, 189]. However, this effect has not been observed in vivo. When investigating the phenomenon in minipigs ( $30 \mathrm{mg} \mathrm{CBD} \cdot \mathrm{kg}^{-1} \cdot \mathrm{day}^{-1}$, oral 5 days), which, like humans, have omnivorous diets and other GI similarities (e.g. $\mathrm{pH}$, transit time, drug absorption), Wray et al. [202] found no detectable (i.e. $<0.5 \mathrm{ng} \cdot \mathrm{mL}^{-1}$ ) $\Delta^{9}-\mathrm{THC}$ or 11 $\mathrm{OH}-\mathrm{THC}$ in any plasma or GI tract samples collected. Consroe et al. [37] also found no detectable $\Delta^{9}$-THC (i.e. $<0.5 \mathrm{ng} \cdot \mathrm{mL}^{-1}$ ) in human plasma following chronic highdose CBD treatment $\left(700 \mathrm{mg}^{-d^{2}{ }^{-1}}\right.$; 30 days). These data suggest that pure $\mathrm{CBD}$ is unlikely to produce a positive drug test result (i.e. indicated by a urinary $\mathrm{THC}-\mathrm{COOH}$ level > $150 \mathrm{ng} \cdot \mathrm{mL}^{-1}[200]$ ) or any intoxicating (ergolytic) effects due to conversion to $\Delta^{9}$-THC. To date, however, no studies have directly investigated whether CBD can elicit a positive drug test result in athletes.

\section{Conclusions}

CBD has been reported to exert a number of physiological, biochemical, and psychological effects, that have the potential to benefit athletes. For instance, there is preliminary supportive evidence for anti-inflammatory, neuroprotective, analgesic, and anxiolytic actions of
$\mathrm{CBD}$ and the possibility it may protect against GI damage associated with inflammation and promote the healing of traumatic skeletal injuries. However, it is important to recognise that these findings are very preliminary, at times inconsistent, and largely derived from preclinical studies. Such studies are limited in their generalisability to athletes (and humans in general), and often administer high doses of CBD that may be difficult to replicate in humans. The central observation is that studies directly investigating CBD and sports performance are lacking, and until these are conducted, we can only speculate in regard to its effects. Nonetheless, this review suggests that rigorous, controlled investigations clarifying the utility of CBD in the sporting context are clearly warranted.

\section{Abbreviations \\ $\Delta^{9}$-THC: $\Delta^{9}$-tetrahydrocannabinol; 5-HT 1 A Serotonin $1 \mathrm{~A}$ receptor; \\ AEA: Anandamide; CV: Cardiovascular; CBD: Cannabidiol; $\mathrm{CB}_{1} \mathrm{R}$ : Cannabinoid \\ $\mathrm{CB}_{1}$ receptor; $\mathrm{CB}_{2} \mathrm{R}$ : Cannabinoid $\mathrm{CB}_{2}$ receptor; $C_{\text {max }}$ : Maximum plasma concentrations; COX: Cyclooxygenase; CYP: Cytochrome P; EIMD: Exercise- induced muscle damage; HI: Hypoxic ischemia; FAAH: Fatty acid amide hydrolase; GI: Gastrointestinal; GPR: G protein-coupled receptor; IL: Interleukin; i.p.: Intraperitoneal; i.v.: Intravenous; NAM: Negative allosteric modulator; NSAID: Non-steroidal anti-inflammatory drug; p.o.: Oral; SPA: Sports performance anxiety; SAD: Social anxiety disorder; TBI: Traumatic brain injury; $T_{C}$ : Core body temperature; $t_{\max }$ : Time to reach maximum plasma concentrations; TRVP $_{1}$ : Transient potential vanilloid receptor type 1 channel; TNF: Tumour necrosis factor; USA: United States of America}

\section{Acknowledgements}

Not applicable.

\section{Authors' Contributions}

All authors were involved in the conception and design of this review. DM was responsible for collating the relevant manuscripts and data. All authors contributed to the drafting and revising of the article, and the final approval of the published version of the manuscript.

\section{Authors' information}

Not applicable.

\section{Funding}

Danielle McCartney, Melissa J Benson, Anastasia S Suraev, and lain S McGregor receive salary support from the Lambert Initiative for Cannabinoid Therapeutics, a philanthropically funded centre for medicinal cannabis research at the University of Sydney. No other sources of funding were used to assist in the preparation of this article.

Availability of Data and Materials

Not applicable.

Ethics Approval and Consent to Participate Not applicable.

Consent for Publication

Not applicable.

\section{Competing Interests}

Danielle McCartney, Melissa J Benson, Ben Desbrow, Christopher Irwin, and Anastasia S Suraev have no potential conflicts of interest with the content of this article. lain S McGregor currently acts as a consultant to Kinoxis

Therapeutics and is named as an inventor on several patents relating to novel cannabinoid therapeutics, none of which relate to sports physiology or medicine. 


\section{Author details}

'The University of Sydney, Faculty of Science, School of Psychology, Sydney, New South Wales 2050, Australia. ${ }^{2}$ The University of Sydney, Lambert Initiative for Cannabinoid Therapeutics, Sydney, New South Wales, Australia. ${ }^{3}$ The University of Sydney, Brain and Mind Centre, Sydney, New South Wales, Australia. ${ }^{4}$ School of Allied Health Sciences, Griffith University, Gold Coast, Queensland, Australia. ${ }^{5}$ Menzies Health Institute Queensland, Gold Coast, Queensland, Australia.

\section{Received: 5 February 2020 Accepted: 17 May 2020}

\section{Published online: 06 July 2020}

\section{References}

1. Adams R, Hunt M, Clark J. Structure of cannabidiol, a product isolated from the marihuana extract of Minnesota wild hemp. J Am Chem Soc. 1940;62: 196-200.

2. Alhamoruni A, Lee A, Wright K, Larvin M, O'sullivan S. Pharmacological effects of cannabinoids on the Caco-2 cell culture model of intestinal permeability. J Pharmacol Exp Ther. 2010;335(1):92-102.

3. Alhamoruni A, Wright K, Larvin M, O'sullivan S. Cannabinoids mediate opposing effects on inflammation-induced intestinal permeability. $\mathrm{Br} \mathrm{J}$ Pharmacol. 2012;165(8):2598-610.

4. Alvarez F, Lafuente H, Rey-Santano C, et al. Neuroprotective effects of the nonpsychoactive cannabinoid cannabidiol in hypoxic-ischemic newborn piglets. Pediatr Res. 2008;64(6):653-8.

5. Appendino G, Gibbons S, Giana A, et al. Antibacterial cannabinoids from Cannabis sativa: a structure- activity study. J Nat Prod. 2008;71(8):1427-30.

6. Arkell TR, Lintzeris N, Kevin RC, et al. Cannabidiol (CBD) content in vaporized cannabis does not prevent tetrahydrocannabinol (THC)-induced impairment of driving and cognition. Psychopharmacology. 2019;236(9):2713-24.

7. Armstrong R, Warren G, Warren J. Mechanisms of exercise-induced muscle fibre injury. Sports Med. 1991;12(3):184-207.

8. Arndt $\mathrm{D}$, de Wit H. Cannabidiol does not dampen responses to emotional stimuli in healthy adults. Cannabis Cannabinoid Res. 2017;2(1):105-13.

9. Arnold J, Allsop D, Lintzeris N, Mcgregor I. Pharmacological actions and associated therapeutic levels of phytocannabinoids: an evidence Check review brokered by the Sax Institute (www.saxinstitute.org.au) for the NSW Ministry of Health. 2016.

10. Arruza L, Pazos M, Mohammed N, et al. Cannabidiol reduces lung injury induced by hypoxic-ischemic brain damage in newborn piglets. Pediatr Res. 2017;82(1):79-86.

11. Bakas T, van Nieuwenhuijzen PS, Devenish SO, McGregor IS, Arnold JC, Chebib M. The direct actions of cannabidiol and 2-arachidonoyl glycerol at GABAA receptors. Pharmacol Res. 2017;119:358-70.

12. Banister SD, Arnold JC, Connor M, Glass M, McGregor IS. Dark classics in chemical neuroscience: delta(9)-tetrahydrocannabinol. ACS Chem Neurosci. 2019;10(5):2160-75.

13. Barata L, Arruza L, Rodríguez M, et al. Neuroprotection by cannabidiol and hypothermia in a piglet model of newborn hypoxic-ischemic brain damage Neuropharmacology. 2019;146:1-11.

14. Belardo C, lannotta M, Boccella S, et al. Oral cannabidiol prevents allodynia and neurological dysfunctions in a mouse model of mild traumatic brain injury. Front Pharmacol. 2019;10(352).

15. Bergamaschi M, Queiroz R, Chagas M, et al. Cannabidiol reduces the anxiety induced by simulated public speaking in treatment-naive social phobia patients. Neuropsychopharmacology. 2011;36(6):1219-26.

16. Bergamaschi M, Queiroz R, Zuardi A, Crippa J. Safety and side effects of cannabidiol, a Cannabis sativa constituent. Curr Drug Saf. 2011;6(4):237-49.

17. Bhattacharyya S, Fusar-Poli P, Borgwardt S, et al. Modulation of mediotemporal and ventrostriatal function in humans by $\Delta 9$ tetrahydrocannabinol: a neural basis for the effects of Cannabis sativa on learning and psychosis. Arch Gen Psychiatry. 2009;66(4):442-51.

18. Bhattacharyya S, Morrison P, Fusar-Poli P, et al. Opposite effects of delta-9tetrahydrocannabinol and cannabidiol on human brain function and psychopathology. Neuropsychopharmacology. 2010;35(3):764-74.

19. Birnbaum A, Karanam A, Marino S, et al. Food effect on pharmacokinetics of cannabidiol oral capsules in adult patients with refractory epilepsy. Epilepsia. In Press.

20. Bonn-Miller M, Loflin M, Thomas B, Marcu J, Hyke T, Vandrey R. Labeling accuracy of cannabidiol extracts sold online. J Am Med Assoc. 2017;318(17):1708-9.
21. Booz G. Cannabidiol as an emergent therapeutic strategy for lessening the impact of inflammation on oxidative stress. Free Radic Biol Med. 2011;51(5): 1054-61.

22. Borgwardt S, Allen $\mathrm{P}$, Bhattacharyya $\mathrm{S}$, et al. Neural basis of $\Delta-9$ tetrahydrocannabinol and cannabidiol: effects during response inhibition. Biol Psychiatry. 2008;64(11):966-73.

23. Borrelli F, Aviello G, Romano B, et al. Cannabidiol, a safe and nonpsychotropic ingredient of the marijuana plant Cannabis sativa, is protective in a murine model of colitis. J Mol Med. 2009:87(11):1111-21.

24. Burstein S. Cannabidiol (CBD) and its analogs: A review of their effects on inflammation. Bioorg Med Chem. 2015;23(7):1377-85.

25. Campos A, Fogaça M, Sonego A, Guimarães F. Cannabidiol, neuroprotection and neuropsychiatric disorders. Pharmacol Res. 2016:112:119-27.

26. Carlini E, Cunha J. Hypnotic and antiepileptic effects of cannabidiol. J Clin Pharmacol. 1981:21(S1):417S-27S.

27. Carlini E, Leite J, Tannhauser M, Berardi A. Cannabidiol and Cannabis sativa extract protect mice and rats against convulsive agents. J Pharm Pharmacol. 1973;25(8):664-5.

28. Carvalho RK, Santos ML, Souza MR, et al. Chronic exposure to cannabidiol induces reproductive toxicity in male Swiss mice (vol 38, pg 1215, 2018). J Appl Toxicol. 2018;38(12):1545.

29. Casey S, Atwal N, Vaughan C. Cannabis constituent synergy in a mouse neuropathic pain model. Pain. 2017;158(12):2452-60.

30. Center for Drug Evaluation and Research, Center for Biologics Evaluation and Research. Estimating the safe starting dose in clinical trials for therapeutics in adult healthy volunteers. 2002.

31. Ceprián M, Jiménez-Sánchez L, Vargas C, Barata L, Hind W, Martínez-Orgado J. Cannabidiol reduces brain damage and improves functional recovery in a neonatal rat model of arterial ischemic stroke. Neuropharmacology. 2017; 116:151-9.

32. Chagas M, Eckeli A, Zuardi A, et al. Cannabidiol can improve complex sleeprelated behaviours associated with rapid eye movement sleep behaviour disorder in Parkinson's disease patients: A case series. J Clin Pharm Ther. 2014;39(5):564-6.

33. Chang Y, Windish D. Cannabinoid hyperemesis relieved by compulsive bathing. Mayo Clin Proc. 2009:84(1):76-8.

34. Cheng D, Low JK, Logge W, Garner B, Karl T. Chronic cannabidiol treatment improves social and object recognition in double transgenic APPswe/ PS1 1 E9 mice. Psychopharmacology. 2014;231(15):3009-17.

35. Cheng D, Spiro AS, Jenner AM, Garner B, Karl T. Long-term cannabidiol treatment prevents the development of social recognition memory deficits in Alzheimer's disease transgenic mice. J Alzheimers Dis. 2014;42(4):1383-96.

36. Clarkson P, Nosaka K, Braun B. Muscle function after exercise-induced muscle damage and rapid adaptation. Med Sci Sports Exerc. 1992;24(5):512-20.

37. Consroe P, Kennedy K, Schram K. Assay of plasma cannabidiol by capillary gas chromatography/ion trap mass spectroscopy following high-dose repeated daily oral administration in humans. Pharmacol Biochem Behav. 1991;40(3):517-22.

38. Cosimo R. The effects of exercise on bone: basic concepts and implications for the prevention of fractures. Clin Cases Miner Bone Metab. 2009;6(3):223.

39. Costa B, Colleoni M, Conti S, et al. Oral anti-inflammatory activity of cannabidiol, a non-psychoactive constituent of Cannabis, in acute carrageenan-induced inflammation in the rat paw. Naunyn Schmiedeberg's Arch Pharmacol. 2004;369(3):294-9

40. Costa B, Giagnoni G, Franke C, Trovato A, Colleoni M. Vanilloid TRPV1 receptor mediates the antihyperalgesic effect of the nonpsychoactive cannabinoid, cannabidiol, in a rat model of acute inflammation. $\mathrm{Br}$ Pharmacol. 2004;143(2):247-50.

41. Costa B, Trovato A, Comelli F, Giagnoni G, Colleoni M. The non-psychoactive cannabis constituent cannabidiol is an orally effective therapeutic agent in rat chronic inflammatory and neuropathic pain. Eur J Pharmacol. 2007; 556(1-3):75-83.

42. Costa B, Vailati S, Colleoni M. SR 141716A, a cannabinoid receptor antagonist, reverses the behavioural effects of anandamide-treated rats. Behav Pharmacol. 1999;10(3):327-31.

43. Craft L, Magyar M, Becker B, Feltz D. The relationship between the Competitive State Anxiety Inventory-2 and sport performance: A metaanalysis. J Sport Exerc Psychol. 2003:25(1):44-65.

44. Crippa J, Derenusson G, Ferrari T, et al. Neural basis of anxiolytic effects of cannabidiol (CBD) in generalized social anxiety disorder: a preliminary report. J Psychopharmacol. 2011;25(1):121-30. 
45. Crippa J, Zuardi A, Garrido G, et al. Effects of cannabidiol (CBD) on regiona cerebral blood flow. Neuropsychopharmacology. 2004;29(2):417-26.

46. Cunha J, Carlini E, Pereira A, et al. Chronic administration of cannabidiol to healthy volunteers and epileptic patients. Pharmacology. 1980;21 (3):175-85.

47. da Silva V, de Freitas B, Dornelles V, et al. Novel insights into mitochondrial molecular targets of iron-induced neurodegeneration: Reversal by cannabidiol. Brain Res Bull. 2018;139:1-8.

48. da Silva V, de Freitas B, Garcia R, et al. Antiapoptotic effects of cannabidiol in an experimental model of cognitive decline induced by brain iron overload. Transl Psychiatry. 2018:8(1):176.

49. Dalton W, Martz R, Lemberger L, Rodda B, Forney R. Influence of cannabidiol on delta-9-tetrahydrocannabinol effects. Clin Pharmacol Therapeut. 1976;19(3):300-9.

50. De Filippis D, Esposito G, Cirillo C, et al. Cannabidiol reduces intestinal inflammation through the control of neuroimmune axis. PLoS One. 2011;6(12):e28159.

51. De Gregorio D, McLaughlin R, Posa L, et al. Cannabidiol modulates serotonergic transmission and reverses both allodynia and anxiety-like behavior in a model of neuropathic pain. Pain. 2019;160(1):136-50.

52. Deiana S, Watanabe A, Yamasaki Y, et al. Plasma and brain pharmacokinetic profile of cannabidiol (CBD), cannabidivarine (CBDV), $\Delta 9$ tetrahydrocannabivarin (THCV) and cannabigerol (CBG) in rats and mice following oral and intraperitoneal administration and CBD action on obsessive-compulsive behaviour. Psychopharmacology. 2012;219(3):859-73.

53. Devinsky O, Cross H, Laux L, et al. Trial of cannabidiol for drug-resistant seizures in the dravet syndrome. N Engl J Med. 2017;376(21):2011-20.

54. Devinsky $\mathrm{O}$, Patel $\mathrm{A}$, Cross $\mathrm{H}$, et al. Effect of cannabidiol on drop seizures in the Lennox-Gastaut Syndrome. N Engl J Med. 2018;378(20):1888-97.

55. Durst R, Danenberg H, Gallily R, et al. Cannabidiol, a nonpsychoactive Cannabis constituent, protects against myocardial ischemic reperfusion injury. Am J Phys Heart Circ Phys. 2007;293(6):H3602-7.

56. El Sohly M, Radwan M, Gul W, Chandra S, Galal A. Phytochemistry of Cannabis sativa L. In: Phytocannabinoids: Springer; 2017. p. 1-36.

57. Elmes MW, Kaczocha M, Berger WT, et al. Fatty acid-binding proteins (FABPs) are intracellular carriers for $\Delta$ 9-tetrahydrocannabinol (THC) and cannabidiol (CBD). J Biol Chem 2015;290:8711-21.

58. Farrimond J, Whalley B, Williams C. Cannabinol and cannabidiol exert opposing effects on rat feeding patterns. Psychopharmacology. 2012;223(1):117-29.

59. Fatouros I, Jamurtas A. Insights into the molecular etiology of exerciseinduced inflammation: opportunities for optimizing performance. J Inflamm Res. 2016;9:175-86.

60. Feng $Y$, Chen F, Yin T, et al. Pharmacologic effects of cannabidiol on acute reperfused myocardial infarction in rabbits: Evaluated with 3.0 T cardiac magnetic resonance imaging and histopathology. J Cardiovasc Pharmacol. 2015;66(4):354-63.

61. Fike J. Industrial hemp: renewed opportunities for an ancient crop. Crit Rev Plant Sci. 2016;35(5-6):406-24.

62. Fouad A, Al-Mulhim A, Jresat I. Cannabidiol treatment ameliorates ischemia/ reperfusion renal injury in rats. Life Sci. 2012;91(7-8):284-92.

63. Fouad A, Jresat I. Therapeutic potential of cannabidiol against ischemia/ reperfusion liver injury in rats. Eur J Pharmacol. 2011;670(1):216-23.

64. Fralick M, Sy E, Hassan A, Burke M, Mostofsky E, Karsies T. Association of concussion with the risk of suicide: a systematic review and meta-analysis. JAMA Neurol. 2019;76(2):144-51.

65. Fride E, Ponde D, Breuer A, Hanuš L. Peripheral, but not central effects of cannabidiol derivatives: Mediation by CB1 and unidentified receptors. Neuropharmacology. 2005;48(8):1117-29.

66. Fujii Y, Ozaki N, Taguchi T, Mizumura K, Furukawa K, Sugiura Y. TRP channels and ASICs mediate mechanical hyperalgesia in models of inflammatory muscle pain and delayed onset muscle soreness. Pain. 2008; 140(2):292-304.

67. Fusar-Poli P, Crippa J, Bhattacharyya S, et al. Distinct effects of $\Delta 9$ tetrahydrocannabinol and cannabidiol on neural activation during emotional processing. Arch Gen Psychiatry. 2009;66(1):95-105.

68. Garberg H, Huun M, Escobar J, et al. Short-term effects of cannabidiol after global hypoxia-ischemia in newborn piglets. Pediatr Res. 2016;80(5):710-8.

69. Garberg H, Solberg R, Barlinn J, Martinez-Orgado J, Løberg E, Saugstad O. High-dose cannabidiol induced hypotension after global hypoxia-ischemia in piglets. Neonatology. 2017;112(2):143-9.

70. Genaro K, Fabris D, Arantes A, Zuardi A, Crippa J, Prado W. Cannabidiol Is a potential therapeutic for the affective-motivational dimension of incision pain in rats. Front Pharmacol. 2017;8(391).
71. Gigli S, Seguella L, Pesce M, et al. Cannabidiol restores intestinal barrier dysfunction and inhibits the apoptotic process induced by Clostridium difficile toxin A in Caco-2 cells. United European Gastroenterol J. 2017;5(8): 1108-15.

72. Greco T, Ferguson L, Giza C, Prins M. Mechanisms underlying vulnerabilities after repeat mild traumatic brain injuries. Exp Neurol. 2019;317.

73. Green B, Kavanagh D, Young R. Being stoned: A review of self-reported cannabis effects. Drug Alcohol Rev. 2003;22(4):453-60.

74. Hainline B, Derman W, Vernec A, et al. International Olympic Committee consensus statement on pain management in elite athletes. Br J Sports Med. 2017:51(17):1245-58.

75. Hammell D, Zhang L, Ma F, et al. Transdermal cannabidiol reduces inflammation and pain-related behaviours in a rat model of arthritis. Eur J Pain. 2016;20(6):936-48.

76. Hanuš L, Meyer S, Muñoz E, Taglialatela-Scafati O, Appendino G Phytocannabinoids: a unified critical inventory. Nat Prod Rep. 2016;33(12): 1357-92.

77. Hao E, Mukhopadhyay P, Cao Z, et al. Cannabidiol Protects against doxorubicin-induced cardiomyopathy by modulating mitochondrial function and biogenesis. Mol Med. 2015;21:38-45.

78. Harris H, Sufka K, Gul W, El Sohly M. Effects of delta-9-tetrahydrocannabinol and cannabidiol on cisplatin-induced neuropathy in mice. Planta Med. 2016; 82(13):1169-72.

79. Hausswirth C, Louis J, Aubry A, Bonnet G, Duffield R. Y LEM. Evidence of disturbed sleep and increased illness in overreached endurance athletes. Med Sci Sports Exerc. 2014;46(5):1036-45.

80. Hayakawa K, Irie K, Sano K, et al. Therapeutic time window of cannabidiol treatment on delayed ischemic damage via high-mobility group box1inhibiting mechanism. Biol Pharm Bull. 2009;32(9):1538-44.

81. Hayakawa K, Mishima K, Irie K, et al. Cannabidiol prevents a post-ischemic injury progressively induced by cerebral ischemia via a high-mobility group box1-inhibiting mechanism. Neuropharmacology. 2008:55(8):1280-6.

82. Hayakawa K, Mishima K, Nozako M, et al. Delayed treatment with cannabidiol has a cerebroprotective action via a cannabinoid receptorindependent myeloperoxidase-inhibiting mechanism. J Neurochem. 2007; 102(5):1488-96.

83. Hayakawa K, Mishima K, Nozako M, et al. Repeated treatment with cannabidiol but not $\Delta$-tetrahydrocannabinol has a neuroprotective effect without the development of tolerance. Neuropharmacology. 2007;52(4): 1079-87.

84. Hillard C. Circulating endocannabinoids: From whence do they come and where are they going? Neuropsychopharmacology. 2018;43(1):155-72.

85. Hiltunen A, Järbe T, Wängdahl K. Cannabinol and cannabidiol in combination: Temperature, open-field activity, and vocalization. Pharmacol Biochem Behav. 1988:30(3):675-8.

86. Hindocha C, Freeman T, Schafer G, et al. Acute effects of delta-9tetrahydrocannabinol, cannabidiol and their combination on facial emotion recognition: A randomised, double-blind, placebo-controlled study in cannabis users. Eur Neuropsychopharmacol. 2015;25(3):325-34.

87. Hoggart B, Ratcliffe S, Ehler E, et al. A multicentre, open-label, follow-on study to assess the long-term maintenance of effect, tolerance and safety of THC/CBD oromucosal spray in the management of neuropathic pain. J Neurol. 2015:262(1):27-40.

88. Hollister L. Actions of various marihuana derivatives in man. Pharmacol Rev. 1971;23(4):349-57.

89. Huestis M, Mazzoni I, Rabin O. Cannabis in sport: anti-doping perspective. Sports Med. 2011;41(11):949-66.

90. Hundal H, Lister R, Evans N, et al. The effects of cannabidiol on persecutory ideation and anxiety in a high trait paranoid group. J Psychopharmacol. 2017:32(3):276-82

91. lannotti F, Pagano E, Moriello A, et al. Effects of non-euphoric plant cannabinoids on muscle quality and performance of dystrophic MDX mice. Br J Pharmacol. 2019;176(10):1568-84

92. Ibeas Bih C, Chen T, Nunn A, Bazelot M, Dallas M, Whalley B. Molecular targets of cannabidiol in neurological disorders. Neurotherapeutics. 2015; 12(4):699-730.

93. Ignatowska-Jankowska B, Jankowski M, Swiergiel A. Cannabidiol decreases body weight gain in rats: Involvement of CB2 receptors. Neurosci Lett. 2011; 490(1):82-4

94. Irving P, labal T, Nwokolo C, et al. A randomized, double-blind, placebocontrolled, parallel-group, pilot study of cannabidiol-rich botanical extract in 
the symptomatic treatment of ulcerative colitis. Inflamm Bowel Dis. 2018; 24(4):714-24.

95. Jadoon K, Tan G, O'Sullivan S. A single dose of cannabidiol reduces blood pressure in healthy volunteers in a randomized crossover study. JCl Insight. 2017;2(12):e93760.

96. Javadi-Paydar M, Nguyen J, Kerr T, et al. Effects of $\Delta 9-\mathrm{THC}$ and cannabidiol vapor inhalation in male and female rats. Psychopharmacology. 2018;235(9):2541-57.

97. Kamins J, Giza C. Concussion-mild traumatic brain injury: Recoverable injury with potential for serious sequelae. Neurosurg Clin. 2016;27(4):441-52.

98. Karniol I, Shirakawa I, Kasinski N, Pfeferman A, Carlini E. Cannabidiol interferes with the effects of $\Delta$ 9-tetrahydrocannabinol in man. Eur J Pharmacol. 1974;28(1):172-7.

99. Kennedy M. Cannabis: Exercise performance and sport. A systematic review. J Sci Med Sport. 2017;20(9):825-9.

100. Khaksar S, Bigdeli M. Correlation between cannabidiol-induced reduction of infarct volume and inflammatory factors expression in ischemic stroke model. Basic Clin Neurosci. 2017;8(2):139-46.

101. King K, Myers A, Soroka-Monzo A, et al. Single and combined effects of $\Delta$ tetrahydrocannabinol and cannabidiol in a mouse model of chemotherapyinduced neuropathic pain. Br J Pharmacol. 2017;174(17):2832-41.

102. Klein M, de Quadros De Bortolli J, Guimarães F, Salum F, Cherubini K, de Figueiredo M. Effects of cannabidiol, a Cannabis sativa constituent, on oral wound healing process in rats: Clinical and histological evaluation. Phytother Res. 2018;32(11):2275-81.

103. Kogan N, Melamed E, Wasserman E, et al. Cannabidiol, a major nonpsychotropic Cannabis constituent enhances fracture healing and stimulates lysyl hydroxylase activity in osteoblasts. J Bone Miner Res. 2015;30(10):190513

104. Kraft B, Frickey N, Kaufmann R, et al. Lack of analgesia by oral standardized Cannabis extract on acute inflammatory pain and hyperalgesia in volunteers. Anesthesiology. 2008;109(1):101-10.

105. Lafuente $H$, Pazos $M$, Alvarez $A$, et al. Effects of cannabidiol and hypothermia on short-term brain damage in new-born piglets after acute hypoxia-ischemia. Front Neurosci. 2016;10:323.

106. Laprairie R, Bagher A, Kelly M, Denovan-Wright E. Cannabidiol is a negative allosteric modulator of the cannabinoid CB 1 receptor. Br J Pharmacol. 2015; 172(20):4790-805.

107. Lattanzi S, Brigo F, Trinka E, et al. Efficacy and safety of cannabidiol in epilepsy: A systematic review and meta-analysis. Drugs. 2018;78(17):1791-804.

108. Leas EC, Nobles AL, Caputi TL, Dredze M, Smith DM, Ayers JW. Trends in Internet searches for cannabidiol (CBD) in the United States. JAMA Netw Open. 2019;2(10):-e1913853.

109. Leeder J, Glaister M, Pizzoferro K, Dawson J, Pedlar C. Sleep duration and quality in elite athletes measured using wristwatch actigraphy. J Sports Sci. 2012:30(6):541-5.

110. Leweke F, Piomelli D, Pahlisch F, et al. Cannabidiol enhances anandamide signaling and alleviates psychotic symptoms of schizophrenia. Transl Psychiatry. 2012;2:e94.

111. Leweke M, Schneider U, Radwan M, Schmidt E, Emrich H. Different effects of nabilone and cannabidiol on binocular depth inversion in man. Pharmacol Biochem Behav. 2000;66(1):175-81.

112. Li D, Lin Z, Meng Q, Wang K, Wu J, Yan H. Cannabidiol administration reduces sublesional cancellous bone loss in rats with severe spinal cord injury. Eur J Pharmacol. 2017;809:13-9.

113. Li H, Kong W, Chambers C, et al. The non-psychoactive phytocannabinoid cannabidiol (CBD) attenuates pro-inflammatory mediators, T cell infiltration, and thermal sensitivity following spinal cord injury in mice. Cell Immunol. 2018;329:1-9.

114. Lichtman A, Lux E, McQuade R, et al. Results of a double-blind, randomized, placebo-controlled study of nabiximols oromucosal spray as an adjunctive therapy in advanced cancer patients with chronic uncontrolled pain. J Pain Symptom Manag. 2018;55(2):179-88.

115. Linares I, Guimaraes F, Eckeli A, et al. No acute effects of cannabidiol on the sleep-wake cycle of healthy subjects: A randomized, double-blind, placebocontrolled, crossover study. Front Pharmacol. 2018;9:315.

116. Linares I, Zuardi A, Pereira L, et al. Cannabidiol presents an inverted Ushaped dose-response curve in a simulated public speaking test. Braz J Psychiatry. 2019;41(1):9-14.

117. Logue D, Madigan S, Delahunt E, Heinen M, Mc Donnell S, Corish C. Low energy availability in athletes: A review of prevalence, dietary patterns, physiological health, and sports performance. Sports Med. 2018;48(1):73-96.
118. Long L, Chesworth R, Huang X, McGregor I, Arnold J, Karl T. A behavioural comparison of acute and chronic Delta(9)-tetrahydrocannabinol and cannabidiol in C57BL/6JArc mice. Int J Neuropsychopharmacol. 2010;13(7): 861-76.

119. Lowe HI, Toyang NJ, McLaughlin W. Potential of cannabidiol for the treatment of viral hepatitis. Pharm Res. 2017;9(1):116.

120. Machida M, Takemasa T. Ibuprofen administration during endurance training cancels running-distance-dependent adaptations of skeletal muscle in mice. J Physiol Pharmacol. 2010;61(5):559-63.

121. Malhotra R. Sleep, recovery, and performance in sports. Neurol Clin. 2017; 35(3):547-57.

122. Maor Y, Yu J, Kuzontkoski PM, Dezube BJ, Zhang X, Groopman JE. Cannabidiol inhibits growth and induces programmed cell death in kaposi sarcoma-associated herpesvirus-infected endothelium. Genes Cancer. 2012; 3(7-8):512-20.

123. Martin-Santos R, Crippa J, Batalla A, et al. Acute effects of a single, oral dose of d9-tetrahydrocannabinol (THC) and cannabidiol (CBD) administration in healthy volunteers. Curr Pharm Des. 2012;18(32):4966-79.

124. Masataka N. Anxiolytic Effects of Repeated Cannabidiol Treatment in Teenagers With Social Anxiety Disorders. Front Psychol. 2019;10:2466.

125. McGregor I, Abelev S, Cohen R. et al, Access to Cannabidiol without a Prescription: A Cross-Country Comparison and Analysis. Int J Drug Policy. Under Review.

126. Merrick J, Lane B, Sebree T, Yaksh T, O'Neill C, Banks S. Identification of psychoactive degradants of cannabidiol in simulated gastric and physiological fluid. Cannabis Cannabinoid Res. 2016;1(1):102-12.

127. Mohammed N, Ceprian M, Jimenez L, Ruth Pazos M, Martínez-Orgado J. Neuroprotective effects of cannabidiol in hypoxic ischemic insult: The therapeutic window in newborn mice. CNS Neurol Dis Drug Targets. 2017; 16(1):102-8.

128. Monti J. Hypnoticlike effects of cannabidiol in the rat. Psychopharmacology. 1977:55(3):263-5

129. Mori M, Meyer E, Soares L, Milani H, Guimarães F, de Oliveira R. Cannabidiol reduces neuroinflammation and promotes neuroplasticity and functional recovery after brain ischemia. Prog Neuro-Psychopharmacol Biol Psychiatry. 2017:75:94-105.

130. Mukhopadhyay P, Rajesh M, Horváth B, et al. Cannabidiol protects against hepatic ischemia/reperfusion injury by attenuating inflammatory signaling and response, oxidative/nitrative stress, and cell death. Free Radic Biol Med. 2011;50(10):1368-81.

131. Murillo-Rodriguez E, Désarnaud F, Prospéro-García O. Diurnal variation of arachidonoylethanolamine, palmitoylethanolamide and oleoylethanolamide in the brain of the rat. Life Sci. 2006;79(1):30-7.

132. Murillo-Rodríguez E, Millán-Aldaco D, Palomero-Rivero M, Mechoulam R, Drucker-Colín R. Cannabidiol, a constituent of Cannabis sativa, modulates sleep in rats. FEBS Lett. 2006;580(18):4337-45.

133. Naftali T, Mechulam R, Marii A, et al. Low-dose cannabidiol is safe but not effective in the treatment for Crohn's disease: A randomized controlled trial. Dig Dis Sci. 2017;62(6):1615-20.

134. Nair A, Jacob S. A simple practice guide for dose conversion between animals and human. J Basic Clin Pharm. 2016:7(2):27-31.

135. Napimoga M, Benatti B, Lima F, et al. Cannabidiol decreases bone resorption by inhibiting RANK/RANKL expression and pro-inflammatory cytokines during experimental periodontitis in rats. Int Immunopharmacol. 2009;9(2):216-22

136. Nichols JM, Kaplan BL. Immune responses regulated by cannabidiol. Cannabis Cannabinoid Res. 2020:5(1):12-31.

137. Nicholson A, Turner C, Stone B, Robson P. Effect of delta-9tetrahydrocannabinol and cannabidiol on nocturnal sleep and early-morning behavior in young adults. J Clin Psychopharmacol. 2004;24(3):305-13.

138. Noreen N, Muhammad F, Akhtar B, Azam F, Anwar MI. Is Cannabidiol a Promising Substance for New Drug Development? A Review of its Potential Therapeutic Applications. Crit Rev Eukaryot Gene Expr. 2018;28(1):73-86.

139. O'Sullivan S, Sun Y, Bennett A, Randall M, Kendall D. Time-dependent vascular actions of cannabidiol in the rat aorta. Eur J Pharmacol. 2009; 612(1-3):61-8.

140. Ota H, Katanosaka K, Murase S, Kashio M, Tominaga M, Mizumura K. TRPV1 and TRPV4 play pivotal roles in delayed onset muscle soreness. PLoS One. 2013;8(6):e65751.

141. Patel D, Omar H, Terry M. Sport-related performance anxiety in young female athletes. J Pediatr Adolesc Gynecol. 2010;23(6):325-35. 
142. Pazos M, Cinquina V, Gómez A, et al. Cannabidiol administration after hypoxia-ischemia to newborn rats reduces long-term brain injury and restores neurobehavioral function. Neuropharmacology. 2012;63(5):776-83.

143. Pazos R, Mohammed N, Lafuente $H$, et al. Mechanisms of cannabidiol neuroprotection in hypoxic-ischemic newborn pigs: Role of 5HT1A and CB2 receptors. Neuropharmacology. 2013;71:282-91.

144. Peterson J, Trappe T, Mylona E, et al. Ibuprofen and acetaminophen: Effect on muscle inflammation after eccentric exercise. Med Sci Sports Exerc. 2003; 35(6):892-6.

145. Philpott H, O'Brien M, McDougall J. Attenuation of early phase inflammation by cannabidiol prevents pain and nerve damage in rat osteoarthritis. Pain. 2017;158(12):2442.

146. Pichini S, Mannocchi G, Berretta $P$, et al. $\Delta$ 9-Tetrahydrocannabinol and Cannabidiol Time Courses in the Sera of "Light Cannabis" Smokers: Discriminating Light Cannabis Use from Illegal and Medical Cannabis Use. Ther Drug Monit. 2020;42(1):151-6.

147. Pisanti S, Malfitano AM, Ciaglia E, et al. Cannabidiol: State of the art and new challenges for therapeutic applications. Pharmacol Ther. 2017;175:133-50.

148. Poklis J, Mulder H, Peace M. The unexpected identification of the cannabimimetic, 5F-ADB, and dextromethorphan in commercially available cannabidiol e-liquids. Forensic Sci Int. 2019;294:e25-7.

149. Ribeiro A, Ferraz-de-Paula V, Pinheiro M, et al. Cannabidiol, a nonpsychotropic plant-derived cannabinoid, decreases inflammation in a murine model of acute lung injury: Role for the adenosine A2A receptor. Eur J Pharmacol. 2012;678(1):78-85.

150. Rossi F, Tortora C, Punzo F, et al. The endocannabinoid/endovanilloid system in bone: From osteoporosis to osteosarcoma. Int J Mol Sci. 2019; 20(8):1919.

151. Russo M, Naro A, Leo A, et al. Evaluating Sativex ${ }^{\circledast}$ in neuropathic pain management: A clinical and neurophysiological assessment in multiple sclerosis. Pain Med. 2016;17(6):1145-54.

152. Sargent $C$, Lastella M, Halson S, Roach $G$. The impact of training schedules on the sleep and fatigue of elite athletes. Chronobiol Int. 2014;31(10):1160-8.

153. Schiavon A, Soares L, Bonato J, Milani H, Guimaraes F, de Oliveira R. Protective effects of cannabidiol against hippocampal cell death and cognitive impairment induced by bilateral common carotid artery occlusion in mice. Neurotox Res. 2014;26(4):307-16.

154. Schicho $R$, Storr M. Topical and systemic cannabidiol improves trinitrobenzene sulfonic acid colitis in mice. Pharmacology. 2012;89(3-4):149-55.

155. Scopinho A, Guimarães F, Corrêa F, Resstel L. Cannabidiol inhibits the hyperphagia induced by cannabinoid-1 or serotonin-1A receptor agonists. Pharmacol Biochem Behav. 2011;98(2):268-72.

156. Serpell M, Ratcliffe S, Hovorka J, et al. A double-blind, randomized, placebocontrolled, parallel group study of THC/CBD spray in peripheral neuropathic pain treatment. Eur J Pain. 2014;18(7):999-1012.

157. Shannon S, Opila-Lehman J. Effectiveness of cannabidiol oil for pediatric anxiety and insomnia as part of posttraumatic stress disorder: A case report. Permanente J. 2016;20(4):108.

158. Smith L. Acute inflammation: The underlying mechanism in delayed onset muscle soreness? Med Sci Sports Exerc. 1991;23(5):542-51.

159. Sofia D, Knobloch L. Comparative effects of various naturally occurring cannabinoids on food, sucrose and water consumption by rats. Pharmacol Biochem Behav. 1976;4(5):591-9.

160. Spindle TR, Cone EJ, Goffi E, et al. Pharmacodynamic effects of vaporized and oral cannabidiol (CBD) and vaporized CBD-dominant cannabis in infrequent cannabis users. Drug Alcohol Depend. 2020;107937.

161. Stanley C, Hind W, Tufarelli C, O'Sullivan S. Cannabidiol causes endotheliumdependent vasorelaxation of human mesenteric arteries via CB1activation. Cardiovasc Res. 2015;107(4):568-78

162. Stanley C, Wheal A, Randall M, O'Sullivan S. Cannabinoids alter endothelial function in the Zucker rat model of type 2 diabetes. Eur J Pharmacol. 2013; 720(1-3):376-82.

163. Stout $\mathrm{S}$, Cimino N. Exogenous cannabinoids as substrates, inhibitors, and inducers of human drug metabolizing enzymes: A systematic review. Drug Metab Rev. 2014;46(1):86-95

164. Sultan S, England T, O'Sullivan S. Acute and chronic effects of cannabidiol on haemodynamics in healthy males. Bethesda: 29th annual symposium of the International Cannabinoid Research Society; 2019.

165. Sultan S, Millar S, England T, O'Sullivan S. A systematic review and metaanalysis of the haemodynamic effects of cannabidiol. Front Pharmacol. 2017;8:81.
166. Taffe M, Creehan K, Vandewater S. Cannabidiol fails to reverse hypothermia or locomotor suppression induced by $\Delta(9)$-tetrahydrocannabinol in Sprague-Dawley rats. Br J Pharmacol. 2015;172(7):1783-91.

167. Tagne A, Pacchetti B, Sodergren M, Cosentino M, Marino F. Cannabidiol for Viral Diseases: Hype or Hope? Cannabis Cannabinoid Res. In Press.

168. Taylor D, Fennessy M. Biphasic nature of the effects of $\Delta 9$ tetrahydrocannabinol on body temperature and brain amines of the rat. Eur J Pharmacol. 1977;46(2):93-9.

169. Taylor L, Crockett J, Tayo B, Morrison G. A phase 1, open-label, parallelgroup, single-dose trial of the pharmacokinetics and safety of cannabidiol (CBD) in subjects with mild to severe hepatic impairment. J Clin Pharmacol. 2019;58(8):1110-9.

170. Taylor L, Gidal B, Blakey G, Tayo B, Morrison G. A phase I, randomized, double-blind, placebo-controlled, single ascending dose, multiple dose, and food effect trial of the safety, tolerability and pharmacokinetics of highly purified cannabidiol in healthy subjects. CNS Drugs. 2018;32(11):1053-67.

171. Tham M, Yilmaz O, Alaverdashvili M, Kelly MEM, Denovan-Wright EM, Laprairie RB. Allosteric and orthosteric pharmacology of cannabidiol and cannabidiol-dimethylheptyl at the type 1 and type 2 cannabinoid receptors. Br J Pharmacol. 2019;176(10):1455-69.

172. Thiele EA, Marsh ED, French JA, et al. Cannabidiol in patients with seizures associated with Lennox-Gastaut syndrome (GWPCARE4): A randomised, doubleblind, placebo-controlled phase 3 trial. Lancet. 2018;391(10125):1085-96.

173. Thomas D, Erdman K, Burke L. American College of Sports Medicine joint position Statement: Nutrition and athletic performance. Med Sci Sports Exerc. 2016:48(3):543-68.

174. Toth C, Jedrzejewski N, Ellis C, Frey W. Cannabinoid-mediated modulation of neuropathic pain and microglial accumulation in a model of murine type I diabetic peripheral neuropathic pain. Mol Pain. 2010;6(1):16.

175. Trappe T, White F, Lambert C, Cesar D, Hellerstein M, Evans W. Effect of ibuprofen and acetaminophen on postexercise muscle protein synthesis. Am J Physiol Endocrinol Metab. 2002;282(3):E551-6.

176. Trinh K, Diep D, Robson H. Marijuana and Its effects on athletic performance: A systematic review. Clin J Sport Med. 2018;28(4):350-7.

177. Ujvary I, Hanus L. Human Metabolites of Cannabidiol: A Review on Their Formation, Biological Activity, and Relevance in Therapy. Cannabis Cannabinoid Res. 2016;1(1):90-101.

178. Valvassori SS, Bavaresco DV, Scaini G, et al. Acute and chronic administration of cannabidiol increases mitochondrial complex and creatine kinase activity in the rat brain. Rev Bras Psiquiatr. 2013;35(4):380-6.

179. Van Klingeren B, Ten Ham M. Antibacterial activity of $\Delta 9$ tetrahydrocannabinol and cannabidiol. Antonie Van Leeuwenhoek. 1976; 42(1-2):9-12.

180. van Wijck K, Lenaerts K, Grootjans J, et al. Physiology and pathophysiology of splanchnic hypoperfusion and intestinal injury during exercise: Strategies for evaluation and prevention. Am J Physiol Gastrointest Liver Physiol. 2012; 303(2):G155-68.

181. Van Wijck K, Lenaerts K, Van Bijnen A, et al. Aggravation of exercise-induced intestinal injury by Ibuprofen in athletes. Med Sci Sports Exerc. 2012;44(12): 2257-62.

182. Varvel S, Wiley J, Yang R, et al. Interactions between THC and cannabidiol in mouse models of cannabinoid activity. Psychopharmacology. 2006;186(2): 226-34.

183. Wachtel S, El Sohly M, Ross S, Ambre J, De Wit H. Comparison of the subjective effects of $\Delta$ 9-tetrahydrocannabinol and marijuana in humans. Psychopharmacology. 2002;161(4):331-9.

184. Walsh NP. Recommendations to maintain immune health in athletes. Eur J Sport Sci. 2018;18(6):820-31.

185. Walsh S, Hepburn C, Kane K, Wainwright C. Acute administration of cannabidiol in vivo suppresses ischaemia-induced cardiac arrhythmias and reduces infarct size when given at reperfusion. Br J Pharmacol. 2010;160(5): 1234-42.

186. Wang Y, Mukhopadhyay P, Cao Z, et al. Cannabidiol attenuates alcoholinduced liver steatosis, metabolic dysregulation, inflammation and neutrophil-mediated injury. Sci Rep. 2017;7(1):12064.

187. Ward S, McAllister S, Kawamura R, Murase R, Neelakantan $H$, Walker E. Cannabidiol inhibits paclitaxel-induced neuropathic pain through 5-HT1A receptors without diminishing nervous system function or chemotherapy efficacy. Br J Pharmacol. 2014;171(3):636-45.

188. Ware M, Jensen D, Barrette A, Vernec A, Derman W. Cannabis and the health and performance of the elite athlete. Clin J Sport Med. 2018;28(5):480-4. 
189. Watanabe $K$, Itokawa $Y$, Yamaori $S$, et al. Conversion of cannabidiol to $\Delta 9$ tetrahydrocannabinol and related cannabinoids in artificial gastric juice, and their pharmacological effects in mice. Forensic Toxicol. 2007;25(1):16-21.

190. Weiss L, Zeira M, Reich S, Slavin S, Raz I, Mechoulam R, Gallily R. Cannabidiol Arrests Onset of Autoimmune Diabetes in NOD Mice. Neuropharmacology. 2008;54(1): 244-9.

191. Weiss L, Zeira M, Reich S, Har-Noy M, Mechoulam R, Slavini S, \& Gallily R. Cannabidiol lowers incidence of diabetes in non-obese diabetic mice. Autoimmunity. 2006;39(2):143-51.

192. Wendt D, Van Loon L, Van Marken Lichtenbelt W. Thermoregulation during exercise in the heat. Sports Med. 2007;37(8):669-82.

193. Wheal A, Cipriano M, Fowler C, Randall M, O'Sullivan S. Cannabidiol improves vasorelaxation in Zucker Diabetic Fatty rats through cyclooxygenase activation. J Pharmacol Exp Ther. 2014;351(2):457-66.

194. Wheal A, Jadoon K, Randall M, O'Sullivan S. In vivo cannabidiol treatment improves endothelium-dependent vasorelaxation in mesenteric arteries of Zucker Diabetic Fatty rats. Front Pharmacol. 2017;8:248.

195. Wiley J, Burston J, Leggett D, et al. CB1 cannabinoid receptor-mediated modulation of food intake in mice. Br J Pharmacol. 2005;145(3):293-300.

196. Wiley J, Martin B. Cannabinoid pharmacological properties common to other centrally acting drugs. Eur J Pharmacol. 2003;471(3):185-93.

197. Williams C, Kirkham T. Anandamide induces overeating: Mediation by central cannabinoid (CB1) receptors. Psychopharmacology. 1999;143(3):315-7.

198. Williams C, Kirkham T. Reversal of $\Delta 9$-THC hyperphagia by SR141716 and naloxone but not dexfenfluramine. Pharmacol Biochem Behav. 2002;71(1-2): 333-40.

199. World Anti-Doping Agency. Summary of Major Modifications and Explanatory Notes. 2018. https://www.wada-ama.org/sites/default/files/ prohibited_list_2018_summary_of_modifications_en.pdf. Accessed 31 Jan 2020.

200. World Anti-Doping Agency. Detection limits for the confirmatory quantification of threshold substances. 2019.

201. World Health Organization. 2019. https://www.who.int/medicines/access/ controlled-substances/UNSG_letter_ECDD41_recommendations_ cannabis 24Jan19.pdf?ua=1. Accessed 31 Jan 2020.

202. Wray L, Stott C, Jones N, Wright S. Cannabidiol does not convert to $\Delta(9)$ tetrahydrocannabinol in an in vivo animal model. Cannabis Cannabinoid Res. 2017;2(1):282-7.

203. Xiong Y, Mahmood A, Chopp M. Current understanding of neuroinflammation after traumatic brain injury and cell-based therapeutic opportunities. Chin J Traumatol. 2018;21(3):137-51.

204. Yi P, Hsiao Y, Tsai C, Jan T, Lu C, Chang F. Serotonergic system in the central nucleus of amygdala mediates cannabidiol-induced sleep alteration. Open Sleep J. 2008;1:58-68.

205. Zou S, Kumar U. Cannabinoid receptors and the endocannabinoid system: signaling and function in the central nervous system. Int J Mol Sci. 2018; 19(3):833.

206. Zuardi A. Cannabidiol: From an inactive cannabinoid to a drug with wide spectrum of action. Rev Bras Psiquiatr. 2008;30(3):271-80.

207. Zuardi A, Cosme R, Graeff F, Guimaraes F. Effects of ipsapirone and cannabidiol on human experimental anxiety. J Psychopharmacol. 1993;7(1S): 82-8.

208. Zuardi A, Rodrigues N, Silva A, et al. Inverted U-shaped dose-response curve of the anxiolytic effect of cannabidiol during public speaking in real life. Front Pharmacol. 2017:8.

\section{Publisher's Note}

Springer Nature remains neutral with regard to jurisdictional claims in published maps and institutional affiliations.

\section{Submit your manuscript to a SpringerOpen ${ }^{\circ}$ journal and benefit from:}

- Convenient online submission

- Rigorous peer review

- Open access: articles freely available online

- High visibility within the field

- Retaining the copyright to your article

Submit your next manuscript at $\boldsymbol{\nabla}$ springeropen.com 